REVISTA DE DERECHO UNED, NÚM. 11, 2012

\title{
EL PACIENTE TESTIGO DE JEHOVÁ, LA NEGATIVA AL TRATAMIENTO MÉDICO EN SITUACIÓN DE GRAVEDAD Y LA CIRCULAR 1/2012 DE LA FISCALÍA GENERAL DEL ESTADO ${ }^{1}$
}

\author{
JEHOVAH'S WITNESS PATIENT'S, REFUSAL TO MEDICAL \\ TREATMENT IN SERIOUS SITUATION AND CIRCULAR 1/2012 \\ OF THE ATTORNEY GENERAL OF STATE
}

\author{
JOSÉ RAMÓN DÍEZ RODRÍGUEZ \\ Abogado \\ Doctor en Derecho \\ Profesor-Tutor UNED
}

\begin{abstract}
Resumen: El paciente testigo de Jehová y su rechazo a determinados tratamientos médicos, en concreto a las transfusiones de sangre, constituye uno de los problemas fundamentales con el que históricamente se ha tenido que enfrentar el derecho sanitario. La actual Ley 41/2002 de autonomía del paciente parece dejar claro el supuesto del paciente mayor de edad y la posibilidad de rechazar tratamientos médicos, pero mayores problemas plantean los supuestos del menor de edad, y especialmente la figura del menor maduro, y el supuesto de la mujer embarazada testigo de Jehová. Será necesario atender a la proporcionalidad de derechos en conflicto para determinar los criterios que en cada caso nos permitan inclinar la balanza a favor de una u otra posición.
\end{abstract}

Palabras Clave: Testigos de Jehová; menor maduro; mujer embarazada; Circular 1/2012, Fiscalía General del Estado.

${ }^{1}$ Este trabajo se inscribe dentro de la investigación financiada por el Ministerio de Ciencia y Tecnología en el proyecto «Optimización y gestión de la información de las instrucciones previas (DER 2010-21129)». 
Abstrac: The Jehovah's Witness patient and their rejection of certain medical treatments, namely blood transfusions, is one of the fundamental problems with which historically had to face the health law. The current Law 41/2002 of patient autonomy seems to clarify the adult patient's adult and their possibility of refusing medical treatment, but major problems posed minor assumptions, especially the mature minor figure, and the course pregnant woman Jehovah's Witness. It will be necessary to address the proportionality of conflicting rights, and determining criteria in each case allow us to tip the balance in favor of one position or another.

Keywords: Jehovah's Witnesses; mature minor; pregnant woman; Circular 1/2012, Attorney General of the State.

Recepción original: 18/09/2012

Aceptación original: 21/09/2012

Sumario: I. Las causas que justifican el rechazo de las transfusiones de sangre por los testigos de Jehová; II. La evolución de la Jurisprudencia española respecto de los testigos de Jehová y las transfusiones de sangre; III. Los derechos implicados en el rechazo al tratamiento médico; IV. El testigo de Jehová mayor de edad y capaz. V. La mujer embarazada testigo de Jehová; VI. El testigo de Jehová menor de edad y su consentimiento; VI.1. El paciente menor de 16 años y negativa de los padres a la transfusión de sangre; VI.2. Pacientes menores de edad, pero mayores de 16 años, que aceptan el tratamiento y sus padres o tutores lo rechazan; VI.3. Pacientes menores de edad con 16 años cumplidos que rechacen el tratamiento, y sus padres o tutores ratifiquen la negativa; VII. Pacientes incapaces, sean o no menores de edad; VIII. La Circular de la Fiscalía General del Estado 1/2012; IX. Conclusiones.

Recientemente se ha publicado por la Fiscalía General del Estado la Circular 1/2012 sobre el tratamiento sustantivo y procesal de los conflictos ante transfusiones de sangre y otras intervenciones médicas sobre menores de edad en caso de riesgo grave, en la que se define el modo de proceder en aquellos supuestos, en los que sea por la razón que sea, se vea comprometido el derecho a la vida o la integridad de un menor de edad².

${ }^{2}$ Estos caso no sólo comprenden los supuestos de los testigos de Jehová y su conocido rechazo a las transfusiones de sangre, sino que como indica FERREIRO GALGUERA, J., «Libertad de conciencia contra legem: Criterios del Tribunal Constitucional en materia de transfusiones», en Foro Revista de Ciencias Jurídicas y Sociales Nueva Época n. ${ }^{\circ}$ 00/2004, Facultad de Derecho, Universidad Complutense de Madrid, Madrid 2004, pag.143 indica que «menos conocida en nuestro país, pero con 
Dicha Circular la considero cuanto menos oportuna, en cuanto que la Ley 41/2002 de 14 de noviembre, básica reguladora de la autonomía del paciente y de derechos y obligaciones en materia de información y documentación clínica, de la que ahora se cumplen diez años, no es muy clara en relación con el consentimiento a tratamientos médicos prestados a menores e incapaces. Recientemente en mi tesis doctoral, identifiqué estos supuestos como una excepción al consentimiento y autonomía del paciente basándome en argumentos similares a los que ahora se recogen en la citada Circular de la Fiscalía General del Estado.

No obstante, antes de desarrollar el problema del paciente testigo de Jehová menor de edad, conviene realizar una mención general a las causas por las que los testigos de Jehová se niegan a la realización de transfusiones de sangre, y el tratamiento que debe dispensarse también al paciente mayor de edad y capaz en estos supuestos.

\section{LAS CAUSAS QUE JUSTIFICAN EL RECHAZO DE LAS TRANS- FUSIONES DE SANGRE POR LOS TESTIGOS DE JEHOVÁ}

Los testigos de Jehová constituyen un grupo religioso surgido de una escisión del protestantismo estadounidense, deben su fundación a Charles Tazel Russell en $1884^{3}$ con la publicación de la revista La Atalaya de Sión, aunque como asociación se crea en 1931, siendo su órgano rector la Watchtower Society de Nueva York. En nuestro país, tienen la consideración legal de confesión religiosa, con personali-

\footnotetext{
gran número de adeptos en otros lugares, se halla el movimiento religioso Christian Science, fundado en Boston en 1879, sus miembros creen que cualquier dolencia puede sanar exclusivamente por la oración y por ello consideran ilícito el recurso a los tratamientos médicos de forma generalizada. Sólo en casos excepcionales admiten analgésicos para mitigar el dolor. Junto a estos grupos existen confesiones que se niegan a recibir productos derivados de animales prohibidos o sagrados, y por lo tanto, rechazan tratamientos basados por ejemplo, en recepción de insulina o la implantación de válvulas cardiacas de origen porcino. Otros grupos, por razones de pudor religioso, impiden a sus fieles femeninas que sean examinadas por médicos varones que no pertenezcan a su confesión.

${ }^{3}$ MARQUEZ, D., en "Transfusiones de sangre a testigos de Jehová», en http://www. extj.org/sangre_temas/sangre_argentina.htm, entrada revisada 25/11/2011 señala que la organización de los Testigos de Jehová fue iniciada por Charles Taze Russel, disidente de un grupo adventista en la década de 1870, en Pensilvania, si bien su actual denominación procede del 1931 bajo el mandato de su segundo presidente: Joshep Rutherford. Previamente, se los denominaba «estudiantes de la Biblia» o «russelitas».
} 
dad jurídica propia reconocida desde su inscripción en el año 1.970 en el Registro de Entidades Religiosas del Ministerio de Justicia.

Los Testigos de Jehová aceptan la gran mayoría de los tratamientos médicos ("No tienen necesidad de médicos los sanos, sino los enfermos...», Lucas 5:31), pero tratándose de transfusiones sanguíneas la situación es totalmente distinta, y amparándose en una interpretación literal de ciertos pasajes de la Biblia justifican su negativa a las mismas, así se indica: "Solamente os abstendréis de comer carne con su alma, es decir, su sangre» (Génesis 9:4), "Nadie de entre vosotros... comerá sangre» (Levítico 17:12), «... porque la vida de toda carne es la sangre; quien la comiere será exterminado» (Levítico 17:14)4. También distinguen entre componentes primarios de la sangre (glóbulos rojos, glóbulos blancos, plaquetas y plasma), y componentes secundarios (la albúmina, factores de coagulación e inmunoglobulinas) que son habitualmente aceptados ${ }^{5}$, debido a que atraviesan de manera natural la barrera placentaria durante la gestación, de esta manera, consideran que esos componentes más simples dejarían de ser considerados «sangre».

Si un Testigo de Jehová acepta una transfusión, por su propia acción manifiesta su deseo de no seguir siendo parte de la referida comunidad, lo que implica también un importante desligamiento social, según el mandato de no tener trato con los que violen la Ley de Dios $^{6}$. Esta situación no se aplica a aquellos miembros que reciben

${ }^{4}$ BESIO, M. y BESIO, F., «Testigos de Jehová y transfusión sanguínea: reflexión desde una ética natural». Revista chilena de obstetricia y ginecología, versión On-line, ISSN 0717-7526, v.71, n.4, Santiago, 2006, en http://www.scielo.cl/ scielo.php?pid=S0717-75262006000400010\&script=sci_arttext, entrada revisada el $25 / 11 / 2011$. Indican que «los fundamentos para rechazar las transfusiones sanguíneas se basan en el mandato explícito de Dios a través de las Escrituras. Quien no acatase la voluntad de Dios no vería cumplida la esperanza de la Resurrección, es decir, perdería el Paraíso, la morada eterna en la tierra ( «Los justos poseerán la tierra, y morarán en ella por siempre», Salmo 37:29)».

${ }^{5}$ Véase FAJARDO, J., IBARRA. S., PEREZ C. ,en «Las Transfusiones Sanguíneas, Testigos de Jehová y Bioetica», en el blog «Bioética y universo Libre», en http://bioeticayuniversolibre.blogspot.com/2009/11/las-transfusiones-sanguineas-testigos.html, (entrada revisada el 25/11/2011) señalan como componentes de la sangre prohibidos por los testigos de Jehová los siguientes: Sangre completa, plasma, leucocitos, glóbulos rojos, plaquetas, y el hecho de almacenar sangre propia del paciente para futuras transfusiones.

Sin embargo, consideran componentes de la sangre permitidos los siguientes: Albúmida, Inmunoglobulinas, preparados hemofílicos (factor VIII y IX), y la desviación de la sangre del paciente a través de una máquina de diálisis u otro tipo de desviación donde la «circulación extracorpórea no se interrumpa».

${ }^{6}$ Esta creencia también esta basada en una interpretación literal de la Biblia, y así se indica. «Si alguno viene a ustedes y no trae esta enseñanza, nunca lo reciban 
una transfusión en contra de su voluntad o los que, habiendo aceptado la transfusión, se arrepienten en el transcurso de un proceso que se les sigue dentro de la comunidad ${ }^{7}$.

Por otro lado, hay que reconocer también que han sido las creencias de este grupo, las que han permitido que se potencien los tratamientos alternativos a la transfusión de sangre, y también el desarrollo de sustitutivos de la misma ${ }^{8}$.

\section{LA EVOLUCIÓN EN LA JURISPRUDENCIA ESPAÑOLA RES- PECTO DE LOS TESTIGOS DE JEHOVÁ Y LAS TRANSFUSIO- NES DE SANGRE}

Los primeros pronunciamientos judiciales sobre testigos de Jehová existentes en nuestro Ordenamiento se refieren a querellas planteadas contra jueces por haber autorizado transfusiones de sangre en contra de la voluntad del paciente, y con ello, entendían que se había vulnerado su derecho a la libertad ideológica y religiosa (art. $16 \mathrm{CE}$ ). Las respuestas de estos primeros pronunciamientos se basan esencialmente en la preeminencia del derecho a la vida sobre la libertad religiosa, y así las repuestas del TS-, en los Autos de 14 de marzo de 1979 y 22 de diciembre de 1983-iban por la consideración de la existencia de una eximente de «estado de necesidad» que excluía la responsabilidad penal ${ }^{9}$, en cuanto que el mal que se trataba de evitar

en casa ni le digan un saludo. Porque el que le dice un saludo es partícipe en sus obras inicuas", (2 Juan 10-11).

${ }^{7}$ Véase BESIO, M. y BESIO, F., «Testigos de Jehová y transfusión sanguínea: ...».

${ }^{8}$ Véase también en la página de Anestiosología Mexicana en Internet, el artículo sin firmar titulado «Implicaciones Médico-Legales de la Hemotransfusión y los Testigos de Jehová (TJ)», en http://www.anestesia.com.mx/art-17.htm (entrada revisada el 14/11/2012) donde se hace una relación de los tratamientos médicos y las técnicas que los testigos de Jehová aceptan.

Terapias aceptadas por los testigos de Jehová: Soluciones cristaloides, soluciones coloides sintéticas, dextranos, almidones, aprotinina, ácido aminocaproico, desmopresina, hierro, perfluorocarbonos.

Técnicas aceptadas por los testigos de Jehová: hipotensión arterial controlada, hipotermia inducida, monitorización de gases arteriales, biometría hemática y química sanguínea.

Técnicas y terapias potencialmente inaceptables por algunos testigos de Jehová, y por lo tanto será necesario consultarles: Eritropoyetina, albúmina humana, circulación extracorporea, sistemas de reutilización de sangre perdida, hemodilución.

${ }^{9}$ En contra BAJO FERNÁNDEZ, M., en «Testigo De Jehová y Transfusión de Sangre», en http://Www.Eutanasia.Ws/Hemeroteca/Z32.Pdf, entrada revisada el 25/11/2011, critica la consideración en estos casos del estado de necesidad ya que indica que dicha causa de exención de la responsabilidad penal va depender de dos 
era superior al mal causado; y en otras se acudía a la aplicación de la eximente de actuar en el ejercicio legítimo de un deber.

El ATC 369/1984, de 20 de junio, estimó otro nuevo límite a la actuación del testigo de Jehová, y concretamente se invocó que el derecho a la libertad religiosa reconocido en el art. 16.1 CE tiene como límite reconocido en la L.O. 7/1980 de Libertad Religiosa «la salud de las personas», y que para salvaguardar dicha salud se justificó el otorgamiento de autorización judicial para una transfusión sanguínea.

Sin embargo, considero que el TC erró en dicho criterio, ya que la L.O. 7/1980 de Libertad Religiosa no establece como límite la "salud de las personas», sino que señala literalmente como límites "la salvaguardia de la seguridad, de la salud y de la moralidad pública, elementos constitutivos del orden público protegido por la Ley», por lo que a la salud que se refiere es a la salud pública y los derechos de terceros, pero nunca a la salud individual de cada sujeto en concreto.

Especial consideración merece también la STS (Sala Penal) de 27 marzo 1990, que versa sobre un caso en la que una mujer después de ser víctima de una agresión quedó encamada en estado

valoraciones, una referente a la ponderación de los bienes en litigio y otra al sentido ético-social de la acción en el conjunto del ordenamiento jurídico. Y señala que desde esta perspectiva no podemos ignorar la importancia que toda la doctrina ha otorgado a la dignidad de la persona humana como "punto de referencia de todos los derechos fundamentales. A ello hay que añadir que la prohibición de los tratos inhumanos y degradantes no es más que una proyección de la dignidad humana y que como principio interpretativo ha de ponderarse también a la hora de saber cuál de los valores en conflicto es preponderante. Por último, ha de tenerse en cuenta que la valoración de los males en conflicto en un estado de necesidad no puede hacerse igual en el supuesto de estado de necesidad propio que en el llamado auxilio necesario. Cuando es el propio necesitado quien, para salvar su vida, realiza agresiones a terceros lesivas de la libertad, la integridad física e, incluso, la propia vida ajena, la valoración ha de hacerse con pautas distintas que cuando es un tercero, ajeno totalmente a la situación de necesidad, quien caprichosamente resuelve la situación de necesidad contra la propia voluntad del necesitado. El caso más extremo que consistiría en una agresión física por parte de quien no se encuentra en una situación de necesidad, contra la voluntad del necesitado, no puede operar, a efectos de exención de responsabilidad criminal, con los mismos elementos valorativos que el caso absolutamente contrario de que sea el propio necesitado quien actúa para resolver el conflicto. En este contexto, puede sostenerse que el mal causado (violación de la libertad religiosa, de la libertad de acción, lesión física, puesta en peligro de la salud por contagio, etc.) es de mayor valor que el evitado (peligro de muerte). Para esta conclusión hemos de atender, además, al hecho de que la situación de conflicto se da ante una probabilidad remota, porque no se trata de «evitar la muerte» sino de conjurar «un peligro de muerte»; al hecho de que se obra contra la voluntad del sujeto y, por último, al hecho de que se faculta a un tercero a agredir a otro para velar por sus intereses. 
inconsciente en la habitación de un hospital, resultando que se personó un sujeto desconocido reclamando la condición de testigo de Jehová de la paciente pidiendo se le negara cualquier transfusión sanguínea, y en un momento de ausencia de los familiares le arrancó el catéter, negándose posteriormente a que se repusiera la cánula y que continuase la transfusión, a consecuencia de todo lo relatado la paciente fallece aquella misma tarde por el Shock hipovolémico, y el procesado fue condenado como autor de un delito de homicidio con la concurrencia con el carácter de muy calificada de la atenuante de obcecación o estado pasional ${ }^{10}$.

Con posterioridad, la STC 166/1996, de 28 de octubre, reconoce por un lado que, salvo causa justificada, la asistencia médica coactiva es una lesión de un derecho fundamental, -reconociendo la doctrina anterior sentada por la STC 120/1990, pero por otro lado, introduce otro criterio delimitador de la autonomía del sujeto cual es la "la lex artis médica», y así manifiesta expresamente en su Fundamento Tercero que la transfusión de sangre es «un remedio cuya utilización, por pertenecer a la lex artis del ejercicio de la profesión médica, sólo puede decidirse por quienes la ejercen y de acuerdo con las exigencias técnicas que en cada caso se presenten y se consideren necesarias para solventarlo» ${ }^{11}$.

Sin embargo hoy en día, a la vista del contenido del art. 5 del Convenio de Oviedo sobre Derechos Humanos y Biomedicina, y de los arts. 2 y 8 de la Ley 41/2002 de autonomía del paciente ${ }^{12}$, se

${ }^{10}$ La mencionada resolución indicó en su F.J. 2. ${ }^{\circ}$ que: «ciertamente, el consentimiento del interesado excluye la tipicidad penal cuando en la definición de ciertos delitos se ha tenido en cuenta dicha voluntad, y la antijuridicidad si el sujeto pasivo tiene libre disposición del bien jurídico afectado; sin embargo, cuando el consentimiento afecta a la vida, bien indisponible, es absolutamente ineficaz», y continuó manifestando que el «dogmatismo y la rigidez de los esquemas morales de la indicada opción religiosa» les conducía a la consideración de dar un valor absoluto al consentimiento, con preeminencia de la libertad de conciencia sobre el derecho a la vida, y que les autorizaba a poner en riesgo o a sacrificar la vida de los fieles por razones trascendentes que surgían de una particular exégesis de los Textos Sagrados, lo que en términos de la sentencia: "puede conducir, y de hecho conducen, a una ofuscación del raciocinio y la pérdida del pleno dominio de la voluntad».

${ }^{11} \mathrm{Y}$ añadió el citado pronunciamiento que «las causas ajenas a la medicina, por respetables que sean -como lo son en este caso-, no pueden interferir o condicionar las exigencias técnicas de la actuación médica».

${ }^{12}$ Véase especialmente los arts 2.2 y 2.6 de la Ley 41/2002 que indican respectivamente que: «toda actuación en el ámbito de la sanidad requiere, con carácter general, el previo consentimiento de los pacientes o usuarios. El consentimiento, que debe obtenerse después de que el paciente reciba una información adecuada, se hará por escrito en los supuestos previstos en la Ley», y que «todo profesional que interviene en la actividad asistencial está obligado no sólo a la correcta prestación de sus técni- 
parece primar la voluntad del paciente mayor de edad y capaz, llegando incluso a constituirse ésta en una de las reglas básicas propias del arte médico, como ha reiterado en numerosas ocasiones nuestros tribunales ${ }^{13}$, y como se recoge también en el vigente Código de Deontología Médica de $2011^{14}$, por lo que difícilmente se podría mantener el criterio de actuación bajo el amparo del «estado de necesidad» o de la consideración de un "deber legítimo de actuar», ni mucho menos de actuar conforme a la «lex artis» cuando ésta impone el respeto a la voluntad expresada por el paciente.

Así, en los últimos pronunciamientos se advierte un claro cambio a favor de la autonomía del paciente, sin que sea óbice para que en alguno de ellos se reconozca la dificultad de fondo para adoptar una decisión ${ }^{15}$. Con más claridad se han pronunciado ex-

cas, sino al cumplimiento de los deberes de información y de documentación clínica, $\mathrm{y}$ al respeto de las decisiones adoptadas libre y voluntariamente por el paciente.»

${ }^{13}$ Ver entre otras las STS 23 de abril de 1992, 26 de septiembre de 2000, 27 de abril y 27 de septiembre de 2001. Así, la propia STS de 27 de junio de 1997, aunque referida a un menor de edad -cuestión que luego analizaremos con posterioridad-, ya parece recoger en términos generales esta idea, y manifestó que: «el adulto capaz puede enfrentar su objeción de conciencia al tratamiento médico, debiéndose respetar su decisión, salvo que con ello ponga en peligro derechos o intereses ajenos, lesione la salud pública u otros bienes que exigen especial protección».

${ }^{14}$ El Código de Deontología Médica del 2011, señala en su art. 12 que: «1. El médico respetará el derecho del paciente a decidir libremente, después de recibir la información adecuada, sobre las opciones clínicas disponibles. Es un deber del médico respetar el derecho del paciente a estar informado en todas y cada una de las fases del proceso asistencial. Como regla general, la información será la suficiente y necesaria para que el paciente pueda tomar decisiones. 2. El médico respetará el rechazo del paciente, total o parcial, a una prueba diagnóstica o a un tratamiento. Deberá informarle de manera comprensible y precisa de las consecuencias que puedan derivarse de persistir en su negativa, dejando constancia de ello en la historia clínica. 3. Si el paciente exigiera del médico un procedimiento que éste, por razones científicas o éticas, juzgase inadecuado o inaceptable, el médico, tras informarle debidamente, quedará dispensado de actuar.4. Cuando el médico atienda a una persona en huelga de hambre, le informará sobre las consecuencias del rechazo a la alimentación, así como de su previsible evolución y pronóstico. Respetará la libertad de quienes decidan de forma consciente y libre realizar huelga de hambre, incluidas las personas privadas de libertad, pudiendo acogerse a la objeción de conciencia si fuese obligado a contrariar esta libertad».

${ }^{15}$ Véase el Auto n. ${ }^{\circ}$ 143/1999 de la AP de Las Palmas donde parece indicar que estamos ante una cuestión extrajurídica, señalando que: «no tiene respuesta ni en la ley, ni en la costumbre, ni en los principios generales del derecho», y continua en su FJ 6. ${ }^{\circ}$ indicando que: "consiste en un conflicto que se plantea puramente en la esfera interna y más íntima del ser humano -su conciencia, su psique- en la que no entra el derecho positivo, como tampoco entra, o no debe entrar, ninguna persona ajena al sujeto en cuestión. Luego, la respuesta judicial a peticiones como la sometida a conocimiento en esta Sala es la de sugerir que la medida a adoptar sea la que dicten las conciencias de enfermo y médico, si logran ponerse de acuerdo en un diálogo 
presamente a favor de la autonomía del paciente el Auto de la AP Vizcaya n. ${ }^{\circ}$ 291/2001 de 6 de julio, y los de la AP de Guipúzcoa n. $^{\circ}$ 2053/2005 de 18 de marzo, y el Auto de 22 de Septiembre de 2004, que versan sobre documentos de instrucciones previas en las que el paciente había dejado manifestada expresamente su oposición a la transfusión de sangre ${ }^{16}$.

\section{LOS DERECHOS IMPLICADOS EN EL RECHAZO AL TRATA- MIENTO MÉDICO}

Nuestra jurisprudencia ha afrontado esencialmente la negativa a la transfusión de sangre de los testigos de Jehová como un conflicto entre el derecho a la vida por un lado con el derecho a la libertad religiosa por otro; y si bien es cierto que en todos los casos es así, en mi opinión, creo además que existe también una confrontación entre el derecho a la vida con el derecho del paciente a su incolumidad corpo$\mathrm{ral}^{17}$, es decir a que no se actúe sobre su cuerpo sin su consentimiento.

estrictamente privado, íntimo, libre de interferencias extrañas; y si tal acuerdo de orden estricta y exclusivamente moral, de conciencia, anímico, no se produce, decidir, como así se hace en el presente supuesto, que prevalezca la postura del enfermo pero imponiendo previamente a éste, o a su familiar más próximo si aquél se encuentra inconsciente, la firma de una declaración escrita exponiendo que le prohíbe al médico el que le realice una transfusión de sangre cualquiera que sea el estado del enfermo en cuestión, y aunque de ello dependa su vida».

${ }^{16}$ No obstante, PÉREZ TRIVIÑO, J. L., en «Testigos de Jehová: entre la autonomía del paciente y el paternalismo justificado», en InDret Revista para el Análisis de Derecho, en http://www.indret.com/pdf/740_es.pdf, entrada revisada 25/11/2011, trata de justificar que el médico tiene derecho a practicar una transfusión sanguínea a un testigo de Jehová aunque éste manifieste su rechazo en testamento vital o instrucciones previas. Para ello, la posibilidad de que esta posición teórica encuentre acomodo en el Ordenamiento Jurídico español radica en la idea de que en las instrucciones previas no pueden dejarse explicitadas demandas contrarias al Ordenamiento Jurídico, tales como la eutanasia (art. 143 del Código Penal), ni contrarias a la lex artis (salvar una vida teniendo los medios adecuados a su alcance). En este sentido, podría interpretarse que la negativa a la transfusión podría entenderse como una actuación contraria a derecho ya que supondría una denegación del deber de auxilio. Por otro lado, la transfusión, en caso de necesidad urgente, podría justificarse en el Código Penal (art. 20.5), fundamentándose en el estado de necesidad, si el mal causado es menor que el que se trata de evitar (ASTS, 14.03.79; 22.12.83). A mi modo de ver ignora Triviño que el consentimiento del paciente ha entrado a formar parte de la lex artis médica.

${ }^{17}$ FERREIRO GALGUERA, J., en "Libertad de conciencia contra legem...», pág. 143 determina que los supuestos de los testigos de Jehová no reflejan siempre "un caso de libertad de conciencia «contra legem» por motivos religiosos, sino que pueden entrar en juego otros derechos distintos, por ejemplo el derecho a la intimidad o a la integridad física o moral de los pacientes. Además en muchos casos la negativa al tratamiento médico no supone una vulneración de un mandato legal, 
Como señaló Arruego Rodríguez ${ }^{18}$ el derecho fundamental a la integridad física y moral posee una vertiente que proscribe cualquier intervención no consentida en el cuerpo en su doble dimensión física y psíquica; es decir, permite al individuo reaccionar frente a injerencias en el sustrato del derecho fundamental que no cuenten con su aquiescencia, y aunque esta segunda faceta implica de facto cierto poder de disposición sobre el propio cuerpo, ha de reseñarse que esta facultad no sería tanto consecuencia del reconocimiento del derecho de libertad, sino el resultado mediato o derivado de una prohibición: la de intervenir en el cuerpo y espíritu del individuo sin contar con su anuencia.

Este aspecto ha sido recogido por la ya reiterada doctrina del TC, iniciada con el pronunciamiento contenido en el Fundamento Jurídico Octavo de la STC 120/1990, mediante el cual se determinó que con el reconocimiento del derecho fundamental a la integridad física y moral (art. $15 \mathrm{CE}$ ) «se protege la inviolabilidad de la persona, no sólo contra ataques dirigidos a lesionar su cuerpo o espíritu, sino también contra toda clase de intervención en esos bienes que carezca del consentimiento de su titular. Por ello, este derecho constitucional resultará afectado cuando se imponga a una persona asistencia médica en contra de su voluntad», y concretada entre otras muchas ${ }^{19}$, recientemente en la STC 37/2011 de $\mathbf{2 8}$ de marzo, donde se señala que la integridad corporal conlleva una facultad negativa, que implica la imposición de un deber de abstención de actuaciones médicas salvo que se encuentren constitucionalmente justificadas. Con ello,

porque en nuestro entorno jurídico la ley no obliga a los ciudadanos a recibir tratamientos contra su voluntad. En algunos supuestos, por tanto, al margen de que exista un interés estatal o deontológico por mantener la salud o la vida de los pacientes, no concurre el efecto esencial de la libertad de conciencia "contra legem», u objeción de conciencia en sentido estricto, a saber la infracción de una norma. Se da simplemente une mera renuncia al ejercicio del derecho a la salud. No obstante, en algunos contextos o respecto algunos pacientes (menores, incapaces), la jurisprudencia ha estimado que mantener la salud o la vida no es un derecho de sus titulares, sino un deber de instancias externas (administración médica, carcelaria...), quienes, de forma subsidiaria se atribuyen funciones de guarda y tutela.

${ }^{18}$ En ARRUEGO RODRÍGUEZ, G.: «El rechazo y la interrupción del tratamiento de soporte vital en el derecho español», en In Dret Revista para el Análisis de Derecho, Barcelona, mayo 2009, pág 10. en http://www.indret.com/pdf/620_es.pdf, entrada revisada $27 / 11 / 2011$.

${ }^{19}$ Así pues, y aunque, el derecho a la integridad física como se ha señalado- se encuentra evidentemente conectado con el derecho a la salud (tal y como se aprecia en la STC 35/1996, fundamento jurídico 3. ${ }^{\circ}$ ), su ámbito constitucionalmente protegido no se reduce exclusivamente a aquellos casos en que exista un riesgo o daño para la salud, pues dicho derecho resulta afectado por toda clase de intervención (en el cuerpo) que carezca del consentimiento de su titular». 
no niego que se pueda invocar el derecho a la libertad religiosa por quien considere vulnerado tal derecho cuando rechace una transfusión de sangre, pero lo que sí reclamo, y echo de menos, es que los Tribunales no se hayan pronunciado sobre si en estos casos se producía una vulneración o no del derecho del paciente a su incolumidad corporal, y por lo tanto a su integridad (art. $15 \mathrm{CE}$ ).

Piénsese que en cualquier otro sujeto, siempre que se trate de una persona capaz y libre en su decisión, si se niega a la aplicación de un determinado tratamiento médico no se valoran los motivos subjetivos que a ello le conducen, y no se cuestiona si tras ello existe una motivación religiosa o de cualquier otro tipo ${ }^{20}$, y sin embargo tratándose de testigos de Jehová parece que sólo se reconoce un supuesto conflicto con su libertad religiosa ${ }^{21}$.

Cuestión bien distinta es la si debe o no de respetarse siempre y en todo caso la voluntad manifestada por los testigos de Jehová, cuestión ésta que examinaremos a continuación.

\section{EL TESTIGO DE JEHOVÁ MAYOR DE EDAD Y CAPAZ}

La mayoría de la doctrina considera que debe de respetarse la voluntad del testigo de Jehová mayor de edad, libre y con capacidad suficiente $^{22}$ para manifestar su rechazo a los tratamientos médicos

${ }^{20}$ En el mismo sentido véase GOMEZ SÁNCHEZ, en «La libertad de creación y producción científica en la Ley de Investigación Biomédica: Objeto, ámbito de aplicación y principios generales de la Ley», en SÁNCHEZ CARO, J y ABELLAN, F. (Coord.) en Investigación Biomédica en España. Aspectos bioéticos, jurídicos y científicos, Editorial Comares, Granada, 2007, pág. 32, cuando indica: «nada importa a la validez del consentimiento la motivación del sujeto pero sí importa que la manifestación de voluntad sea libre, esté, pues exenta de coacción, no esté motivada por una presión exterior y se haya adoptado después de recibir una información adecuada».

${ }^{21}$ En el mismo sentido véase SEOANE, J. A., en «El perímetro de la objeción de conciencia médica» en In Dret Revista para el Análisis del Derecho, Barcelona, Octubre de 2009, y en ww.raco.cat/index.php/InDret/article/viewFile/141382/192893ttp pág. 7, entrada revisada el 25/11/2011, donde señala que: »en concreto, la negativa de un paciente testigo de Jehová a recibir una transfusión de sangre forma parte del contenido esencial de su derecho fundamental a la integridad física (art. 15 CE; STC 120/1990, de 27 de junio, FJ 8, y STC 154/2002, de 18 de julio, FJ 9) y de su derecho fundamental a la libertad religiosa (art. $16 \mathrm{CE}$ )».

${ }^{22}$ FERREIRO GALGUERA, en «Libertad de conciencia contra legem...», pág.149 ss., pone de manifiesto que tras la STC 120/1990 concerniente a la huelga de hambre suicida de los presos del GRAPO, al desarrollar el derecho a la vida, después reindicar que no comprende un derecho a la muerte manifiesta que "la decisión de vivir depende de la libertad, concibiéndolo como una manifestación del "agere licere», y en ello el autor funda que " por tanto, la decisión de un adulto capaz que se opusiera a una transfusión de sangre por motivos religiosos no sólo estaría amparada por el 
que estime, incluso cuando con ello ponga en peligro su vida ${ }^{23}$; pero no es menos cierto que resultan polémicos los supuestos en los que se produce el fallecimiento del paciente que se niega a la transfusión, sobre todo cuando resulta acreditado que la misma le hubiera salvado la vida con una alta probabilidad.

Desde el punto de vista bioético, los dos principios que eventualmente pueden entrar en conflicto son, por un lado, la autonomía del paciente, esto es, su capacidad de autogobierno acerca de sus propios intereses y valores, que le puede conducir a rechazar un tratamiento necesario para su vida, y por otro lado, su vida o integridad y el deber de los médicos de preservar la salud y la vida que se fundamenta en el principio de beneficencia.

Hay sectores doctrinales, sobre todo penalistas que para resolver esta dicotomía, parten de la idea de excluir en estos casos el problema del consentimiento, así Tamarit Sumilla ${ }^{24}$ señala que frente al empeño en abordar la situación como una cuestión de consentimiento, debe aclararse que parece más adecuado entender la conducta del testigo de Jehová que rechaza el tratamiento "como una autolesión o autopuesta en peligro», de manera que ésta "se desenvuelve exclusivamente en el ámbito de responsabilidad de la víctima, sin que quepa atribuirlo a las esferas de responsabilidad o competencia de terceros intervinientes $y$, por lo tanto, sin posibilidad de imputación objetiva del resultado. Con ello se resuelve el problema ya en sede de tipicidad, negando el carácter típicamente relevante del comportamiento activo u omisivo de terceros...» ${ }^{25}$.

Otras posturas, tratan de justificar que no toda petición del paciente debe de ser atendible desde el punto de vista médico, y en con-

ejercicio de la libertad religiosa, sino también por ese "agere licere», esto es, ese derecho a la autodeterminación que se deriva de la libertad de oponerse a la asistencia médica, que no olvidemos es un valor superior del Ordenamiento Jurídico».

${ }^{23}$ Véase artículo 2.4 de la Ley 41/2002, de 14 de noviembre: "Todo paciente o usuario tiene derecho a negarse al tratamiento, excepto en los casos determinados en la Ley. Su negativa al tratamiento constará por escrito.»

${ }^{24}$ Véase TAMARIT SUMILLA, J. M.: «Responsabilidad penal de terceros ante la negativa a la transfusión de sangre de testigo de Jehová menor de edad con resultado de muerte», en www.westlaw.es

${ }^{25}$ Este planteamiento es criticado por ESPINOSA LABELLA, M., en "Comisión por omisión e imprudencia en la doctrina y la jurisprudencia», en www. westlaw.es, ref. BIB 2009/453, entrada revisada 25/11/2011, manifestando que se parte de una posición errónea sobre la voluntad del Testigo de Jehová ya que, por su propia concepción religiosa, difícilmente puede querer el suicidio sino que, más bien querrá que no se violente su idea religiosa sobre las transfusiones de sangre, aunque pueda perder la vida, si bien éste no es su deseo. Es decir, que el conflicto no es entre derecho a morir y el derecho a la vida sino entre sus creencias religiosas y el derecho a la vida. 
creto consideran que la petición de que no se realice una transfusión de sangre, cuando de ello depende la vida del sujeto, es una petición extravagante o contraria a la «lex artis» ${ }^{26}$.

Pérez Triviño parte de la idea de presuponer que los Testigos de Jehová no son un club de suicidas, y que para ellos la obediencia a los mandatos divinos es una obligación de primer orden, pero matiza que no se debe de olvidar, por otro lado, que la conservación de la vida también es un bien jurídico relevante, y que el Estado a través de la organización sanitaria, tiene una posición de garante de la salud del paciente ${ }^{27}$. El autor, parte del concepto de autonomía fijado por Kant, y la consideración de sujeto autónomo únicamente a aquel que es capaz de determinar el sentido de sus acciones conforme a decisiones racionales que no sean consecuencia de imposiciones externas, de esta manera determina que no toda petición del paciente debe de ser atendida, y concretamente las peticiones irracionales o las influenciadas por terceros no deben de respetarse por no proceder de un ser verdaderamente autónomo ${ }^{28}$.

Así, se pone de relieve que en el apartado de creencias religiosas hay que distinguir entre cuestiones de carácter valorativo respecto de las cuales no tiene sentido preguntarse si son verdaderas o falsas, de aquellas otras creencias (no ya valores), que son comprobables empíricamente y respecto de las que se ha demostrado científicamente que son falsas ${ }^{29}$, y -señala que- «cuando está comprobado su falsedad

${ }^{26}$ En RODRÍGUEZ MOURULLO, G., en La omisión de socorro en el Código penal, Madrid, 1966, págs. 251-252., señala que hay obligación de socorrer al profesional que ha perdido el «dominio de su arte» como el torero que quiere rematar la faena pese a haber sufrido una cogida o el boxeador incapaz de defensa a consecuencia de los golpes. Pero, señala Bajo Fernández que a su juicio cuando el sujeto se opone a una mediación salvadora que, con intención de socorro, implica, sin embargo, algún riesgo para el periculante, la voluntad contraria al socorro elimina, a si juicio el deber de socorrer, y que este es el caso del Testigo de Jehová.

${ }^{27}$ Señala PÉREZ TRIVIÑO, «Testigos de Jehová...», pág. 9: respecto a la posición de garante del Estado señala que «parece claro que si el sujeto ante la situación de gravedad decide no acudir a los especialistas sanitarios será su propia responsabilidad. En cambio, si su opción es ser tratado por los profesionales sanitarios, especialmente, los que integran el sistema público de salud, entonces, está bajo el amparo del Estado y éste tiene un deber positivo prima facie de evitar la muerte de una persona».

${ }^{28} \mathrm{El}$ autor cita como ejemplos los siguientes -piénsese en que un paciente guiado por sus ideas religiosas o espirituales pidiera que se le cortara un dedo para expiar determinas culpas, o piénsese en que una mujer musulmana pidiera expresamente la mutilación genital-, no por ello debería de ser atendida.

${ }^{29}$ PÉREZ TRIVIÑO, «Testigos de Jehová...», págs. 10 y ss. pone de relieve varias contradicciones y evidencias científicas, por ejemplo cuando señala que: «tampoco deja de sorprender que la negativa a las transfusiones de sangre no sea absoluta. Según una directriz del año 2000 habría componentes sanguíneos primarios que no 
no pueden conculcar otros derechos», sobre todo cuando son de tanta transcendencia como el derecho a la vida. Concluye indicando que la transfusión no supone una violación de las creencias puramente religiosas de los testigos de Jehová, sino que afecta a las creencias de carácter empírico, fácilmente comprobables, y por ello las califica de «creencias irracionales» ${ }^{30}$. El deber de respetarlas en estos

pueden ser transfundidos: los glóbulos rojos, los glóbulos bancos, plaquetas y plasma. Pero sí lo pueden ser los componentes secundarios: la albúmina, los factores de coagulación y las inmunoglobinas. La razón de este permiso de transfusión de estas sustancias sanguíneas es que atraviesan de manera natural la barrera placentaria durante la gestación, por lo que no tiene la misma connotación que los componentes primarios. Ahora bien, la distinción entre productos sanguíneos primarios y secundarios no parece ser clara y diáfana. Según MARUMOTO: «La nueva directriz es de alguna manera arbitraria acerca de si un producto es considerado primario o secundario. Cualquier producto derivado de una "componente primario» puede ser considerado secundario; sin embargo, hay muchas zonas grises». Ejemplificando tal idea, MARUMOTO señala que: «Por ejemplo, los glóbulos rojos son procesados por reducción de leucocitos e irradiación, y el plasma puede ser procesado a través de fraccionación y tratamiento con detergentes solventes en productos secundarios. No está claro si estos productos son considerados primarios o secundarios bajo la nueva directriz». En este sentido, es preciso recordar que los testigos de Jehová aceptan en la actualidad el trasplante de órganos y la vacunación, prácticas que inicialmente habían rechazado y que recientemente han matizado su rechazo a las transfusiones sanguíneas pues aceptan tratamiento médico alternativo sin sangre completa y sin hemoderivados tales como los cuatro componentes principales de la sangre: glóbulos rojos, glóbulos blancos, plasma y plaquetas. Por otro lado, algunos testigos sí aceptan fracciones sanguíneas menores. También pone de manifiesto las diferentes interpretaciones que permite la Biblia respecto de la sangre. Por otro lado, critica la creencia de los Testigos de Jehová sobre la naturaleza de la sangre como esencia de la vida, manifestando que según la Biblia solo tendrían la consideración de seres vivos aquellos que poseen sangre, lo cual dejaría fuera de la clase de organismos vivos a los hongos, bacterias, protozoos e incluso y a las plantas, y añade que la sangre es un tejido más formada por un grupo de células especializadas en una determina función al igual que lo es el tejido muscular o el esquelético, resultando que los Testigos de Jehová consideran la sangre como la esencia de lo vivo de lo que no existen evidencias científicas. Por último indica que los Testigos de Jehová aducen razones científico-médicas, de peligro para la salud por contagios transfusional, pero no se puede ignorar que los avances científicos y la selección del donante permiten adoptar medidas de higiene al respecto.

${ }^{30}$ Por ejemplo señala CASAS-MARTíNEZ, M.L., en «Análisis Bioético del embarazo en Testigos de Jehová y el rechazo transfusional» en http://www.aebioetica. org/archivos/03-BIOÉTICA-73.pdf, (entrada revisada el 25/11/2011), pone de relieve que la mayoría de los productos aceptados por las Testigos de Jehová embarazadas se limitan a aquellos que pasan a través de la barrera placentaria durante un embarazo, por ello pueden aceptar estos llamados «componentes menores» como asunto de conciencia. Como serían plaquetas, proteínas y otros elementos químicos propios del plasma. El razonamiento se basa en que si Jehová permite que estos productos pasen de la madre al feto, es lógico concluir que Dios no violaría su propia ley. Este argumento suena muy razonable, si no fuera por el hecho de que la ciencia médica ha demostrado que casi todos los componentes sanguíneos pasan a 
$\operatorname{casos}^{31}$, -indica-, decae frente al deber de beneficencia del médico cuando se enfrenta a la preservación de la vida del paciente ${ }^{32}$. De lo contrario -matiza- se convertiría la libertad religiosa en un «superderecho» frente al que cualquier actuación debería ceder, y cualquier ciudadano podría objetar la aplicación de una norma estatal que atente contra cualquiera de sus creencias y en su defensa podrá alegar la omnisciencia o el mayor poder o sabiduría de su Dios, incluso facultándole para no respetar normas esenciales de la convivencia social ${ }^{33}$.

La postura de Pérez Triviño pone de manifiesto un aspecto esencial, y es que no existe el automatismo entre todo lo que pide el paciente y la actuación médica, y nos pone de manifiesto que la generalización de ser siempre prioritaria la religión o las creencias de un sujeto nos puede conducir a graves consecuencias. Sin embargo, creo que la posición de Pérez Triviño presenta un punto débil y es precisamente que nos obligaría, siempre que algún paciente se negara a un tratamiento, a indagar cuales son las razones que subyacen en el fondo de la consciencia del referido sujeto, y luego tratar de determinar si estas son o no falsas desde el punto de vista científico.

En estos casos se nos plantearían enormes problemas y debemos cuestionarnos: ¿debe el médico determinar si esa petición es o no racional?, y por consiguiente, si el facultativo se equivoca en su análisis ¿podría surgir una nueva fuente de responsabilidad para el

través de la barrera de la placenta, incluyendo cierta cantidad de elementos formes, como los eritrocitos.

${ }^{31}$ PÉREZ TRIVIÑO, «Testigos de Jehová...», pág. 19, señala que: «El hecho de que un juicio falso forme parte de una doctrina comprehensiva y de carácter global como es una doctrina religiosa, no la hace verdadera, -incide- ni la convierte en más respetable. Y cuando esas creencias irracionales entran en conflicto con la preservación de la vida deben quedar relegadas».

${ }^{32}$ En un mismo sentido se pronuncia FEINBERG, J., en Harm to Self, Oxford University Press, Oxford, 1.986, cuando analiza el caso de un paciente que rechaza un tratamiento que probablemente le salvará la vida basándose para ello en una creencia que es errónea. En estos supuestos en los que hay una creencia errónea y el riesgo es perder la vida, los estándares de validez para aceptar el rechazo del enfermo deben ser más altos: «Intervenir para forzar al paciente a recibir el tratamiento es como evitar que un individuo tome té envenenado cuando sinceramente insiste que el arsénico que ha puesto en la taza es azúcar. En ningún caso hay deseo de morir, y de aquí que en ninguno de los dos casos haya invasión de su autonomía».

${ }^{33}$ Véase en GARZÓN VALDÉS, E., "¿Es éticamente justificable el paternalismo jurídico?, Doxa, 5, 1.988, págs. 155 y ss. cuando señala que: «hay razones para el paternalismo justificado cuando un individuo ignora elementos relevantes de la situación en la que se tiene que actuar (como es el caso de quien desconoce los efectos de ciertos medicamentos o drogas) o cuando dicho sujeto, que acepta la importancia de un determinado bien y no desea ponerlo en peligro, se niega utilizar los medios necesarios para salvaguardarlo, pudiendo disponer fácilmente de ellos». 
médico que erróneamente considera, o no, que la petición del sujeto está basada en aspectos verdaderos o falsos?, y que pasaría ¿si el facultativo piensa que la motivación de un sujeto es una y luego resulta que era otra?. ¿Por qué tenemos que cuestionar la actuación de los testigos de Jehová, y no todos y cada uno de los casos en los que el paciente pide que no le apliquen un determinado tratamiento? Y ¿quién valora y bajo qué criterios si la petición el sujeto es o no racional? Piénsese en aquellos supuestos en los que el médico pueda ser Testigo de Jehová y bajo su prisma pudiera ser irracional realizar la transfusión ${ }^{34}$.

Tampoco considero adecuado el argumento que indica que el paciente al acudir a una institución sanitaria, se encuentra bajo la guarda y custodia de ésta, y que por lo tanto, se le puedan imponer tratamientos en contra de su voluntad, ya que precisamente la Ley 41/2002 se dictó para aplicarla expresamente en el ámbito sanitario, y es la que recoge el principio de respeto a la autonomía de la voluntad del paciente, constituyendo precisamente ese respeto al consentimiento del paciente un elemento más de la «lex artis» médica.

Por el contrario, sí me parece muy acertada la posición de Pérez Triviño, respecto a situar el problema en el campo de la proporcionalidad de derechos en sacrificio y justificar la preeminencia de cada uno de ellos según las circunstancias del caso en concreto, y así cuando el paciente sea un sujeto libre y capaz parece que el sentir de la Ley 41/2002 permite rechazar tratamientos médicos, aún cuando estos tuvieran fundados visos de salvarle la vida, primando su autonomía y que el paciente sea el protagonista del proyecto vital que él mismo ha elegido ${ }^{35}$.

${ }^{34}$ De la misma manera, creo que el fundamentar cualquier disensión respecto de que creencias se respetan y cuáles no debería de ser muy bien fundamentada para no vulnerar el principio de igualdad de trato de unas sobre otras.

${ }^{35}$ En BAJO FERNÁNDEZ, en «Testigo De Jehová...», señala que en cuanto a si es posiblemente tipificable la actitud del Testigo de Jehová que no puede calificarse de auxilio omisivo al suicidio, pues la conducta consistente en no realizar la transfusión no puede ser auxilio omisivo al suicidio simplemente porque no hay suicida, entendiendo que el suicidio sólo se produce en el caso en que el sujeto «tiene intención de morir». Para que exista suicidio es imprescindible que el sujeto dirija su voluntad a la producción de la muerte, así no hay voluntad suicida cuando el sujeto se pone en peligro grave de muerte con diversos fines desplegando medios, aunque sean mínimos, para conservar la vida, por ejemplo, no es suicida quien participa en un duelo, ni el testigo de Jehová que, sin desear su muerte, sino pretendiendo permanecer vivo, se niega a la transfusión de sangre consintiendo en la utilización de cualquier otro medio de asistencia que pueda evitar el resultado letal. Tampoco es suicida el soldado que realiza una actividad arriesgada en cumplimiento de sus deberes militares, ni el torero, ni el trapecista. Al igual que en estos casos, indica «el Testigo de Jehová no 
No obstante todo lo expuesto, no ignoro la diatriba que se nos puede generar en algunos casos primando la autonomía de las personas capaces y mayores de edad, en relación con la duda de si podría considerarse, que las personas que profesan unas determinadas creencias -o incluso piénsese más allá del caso aquí tratado, por ejemplo si pertenecieran a una secta-, pudieran tener sus facultades mentales afectadas o condicionadas, y por lo tanto, limitada su libertad, cuestión que estimo habría que valorar en cada caso en concreto.

\section{LA MUJER EMBARAZADA TESTIGO DE JEHOVÁ}

Un supuesto más complicado lo constituye el caso de que la mujer testigo de Jehová se encuentre embarazada en el preciso momento en el que necesita una transfusión sangre y de ella dependa su vida y la de su hijo/a. En estos casos, y siempre que no se pudiera aislar la vida de ese hijo/a, creo que, en cuanto que se ven implicados derechos de terceros, operaría el límite reconocido expresamente en el art. 3.1 de la Ley Orgánica 7/1980 de Libertad Religiosa ${ }^{36}$.

En este caso, pudiera existir un perjuicio para un tercero que es el embrión ya que el embrión no profesa, ni puede profesar, religión alguna, ni tampoco los padres pueden garantizar que aún educán-

es un suicida porque no quiere su propia muerte, tratándose más bien de una persona que quiere vivir, aunque no a toda costa, ni a cualquier precio, como tampoco es suicida la mujer católica que no quiere abortar prefiriendo correr los riesgos de muerte que le auguran los médicos o quien se niega a la amputación del miembro canceroso». Esta actitud, ni psicológica ni jurídicamente puede calificarse de suicida. En cuanto a si existe un deber jurídico de actuar o deber de garantizar que la muerte del paciente no se produzca, lo que daría lugar a responder de la muerte en comisión por omisión, manifiesta que resulta claro que tanto la Ley como la relación contractual que une al médico con el paciente, "contra la voluntad del paciente no hay posición de garante del médico». Y por último, señala que su juicio no hay tampoco omisión del deber de socorro, en el caso hipotético de inhibición del médico, porque la acción esperada y no realizada (transfusión, intervención quirúrgica) no es un socorro en sentido estricto, si entraña riesgos, aunque sean remotos, para la salud del periculante que, además, éste no quiere asumir. Incluso se ha sostenido que no hay persona «desamparada» si se trata de un sujeto responsable que actúa libremente. Reconozco, sin embargo, lo discutible de la cuestión por cuanto se ha sostenido que hay obligación de socorrer al suicida, es decir, que no es suficiente la simple oposición de socorro para eliminar el deber de socorrer.

${ }^{36}$ Art. 3.1 de la L.O. 7/1980: "El ejercicio de los derechos dimanantes de la Libertad Religiosa y de Culto tiene como único límite la protección del derecho de los demás al ejercicio de sus libertades públicas y derechos fundamentales, así como la salvaguardia de la seguridad, de la salud y de la moralidad pública, elementos constitutivos del orden público protegido por la Ley en el ámbito de una sociedad democrática». 
dolo bajo sus creencias éstas serán compartidas en el futuro por el nasciturus, y no debemos olvidar que sin la vida no hay posibilidad de que ese sujeto pudiera aceptar o no las creencias de los testigos de Jehová en un hipotético momento futuro ${ }^{37}$.

Este argumento encontraría refuerzo en la mención que realiza la STC 53/1985 de considerar al nasciturus como «vida humana en formación» y como "bien jurídico susceptible de protección al amparo del art. 15 C.E., que es cuanto más protegible cuanto se acerque al momento de su viabilidad», por lo tanto existe ese tercero susceptible de protección, que constituye un ser autónomo con ADN propio, y siendo esta su consideración debe prevalecer sobre la libertad religiosa y la incolumidad corporal de la madre que se niega ante una transfusión de sangre.

No obstante, creo que se pueden fijar como criterios generales de actuación los siguientes:

a) En primer lugar, se debería explicar a la paciente la gravedad de la situación con las implicaciones respecto a la vida del feto, para que pudiera otorgar su consentimiento a la transfusión.

b) En su defecto, se tratará en la medida de lo posible de conjugar los dos intereses, posponiendo la intervención al momento de viabilidad del feto si es posible, y realizar maniobras de rescate fetal. Es posible que la madre acepte intervención de rescate en el feto, aunque niegue el tratamiento propio, esta actuación deberá de ser consentida por la paciente ${ }^{38}$. Esta opción podría plantear un

${ }^{37}$ Véase CASAS-MARTÍNEZ, "Análisis Bioético del embarazo...» (entrada revisada el 25/11/2011). Para solucionar este difícil problema parte de la consideración de la actuación del paciente como una manifestación del derecho a la objeción de conciencia a un tratamiento médico, y como tal, está sujeta a límites y a ciertas particularidades tales como: 1) que la objeción de conciencia no es un derecho general, sino excepcional, y que debe de argumentarse en su invocación una razón justificada; 2) y que en todo caso no debe producir directamente daños a tercero; 3) y que las condiciones que determinan esta excepción vienen dadas por la naturaleza del bien jurídico protegido, y por consiguiente, será preciso determinar las consecuencias que el incumplimiento de un deber determinado pueden acarrear y resolver a favor del bien jurídico preponderante en cada caso.

${ }^{38}$ Los embriones o fetos menores de 25 semanas no tienen viabilidad ante la inminente muerte de la madre, por lo que éticamente debería hacerse un esfuerzo para esperar las semanas necesarias para inducir un parto o realizar una cesárea. Tratándose de un feto cercano a la viabilidad, si es posible deberá acudirse a los medios actuales de la perinatología, como es el uso de cordocentesis con transfusión homóloga. Resultando ser un feto viable, la posibilidad de inducción de parto, cesárea y aún cesárea postmortem, así como la cordocentesis con transfusión homóloga vuelve a ser una maniobra electiva en este caso. Nuevamente se hace evidente la firma de una aceptación para dicho procedimiento por la madre antes de su muerte, 
nuevo problema ético cual sería en algunos casos el del abandono y cuidado del menor, sobre todo en los casos en los que no haya padre conocido, pero sin duda ésta es otra cuestión ${ }^{39}$ que excede del análisis aquí planteado.

c) En los supuestos de urgencia, y cuando no sea posible conjugar ambos intereses, de la madre y del hijo, entiendo que se deberá de solicitar autorización judicial exponiendo los peligros que pudiera acaecer para el feto, y valorando los intereses en conflicto y el conjunto de circunstancias resuelva lo que estime procedente ${ }^{40}$.

\section{EL TESTIGO DE JEHOVÁ MENOR DE EDAD Y SU CONSEN- TIMIENTO}

La redacción literal del art. 9.3.c de la Ley 41/2002, plantea enormes dudas e interrogantes respecto al consentimiento que deben de prestar los menores de edad en relación con los tratamientos médicos,

puesto que después, y no habiendo manifestado su opción, la decisión sería del padre o familiar cercano.

${ }^{39}$ La Corte Suprema de Connecticut en 1996 resolvió el conocido caso Hospital Stanford vs. Vega, con el siguiente supuesto de hecho: a la Sra. Vega después de dar a luz se le presentó una hemorragia, y el facultativo solicitó al Juez una orden para realizar la transfusión de sangre alegando el interés del Estado para prevenir el «abandono» de su bebé, interés que indicaba primaba sobre el derecho de ella a rechazar una transfusión de sangre. El Juez de instancia accedió a la petición, pero la Corte Suprema de Connecticut, en una decisión por 5-0 revocó la orden, considerando que la autodeterminación física de la paciente era superior y debía de ser respetada.

${ }^{40}$ CASAS-MARTÍNEZ, "Análisis Bioético del embarazo...», señala al respecto que «Toda persona tiene derecho a su bien, y la vida es un bien mínimo en una sociedad democrática. El derecho a la vida, no es deber máximo, de consenso, sino el más mínimo, por lo cual no puede ser negociado, a menos que existiera una razón específica (guerra, pena de muerte, defensa propia), caso que no concuerda con el estado del feto». Y añade que desde el punto de vista exclusivamente del principialismo bioético, esta cuestión se podría también solucionar atendiendo a la teoría de la jerarquización de principios bioéticos formulada por Diego Gracia, y que parte de la consideración de que los cuatro principios bioéticos (autonomía, beneficencia, no maleficencia y justicia), lejos de ser del mismo nivel, se hallan estructurados en dos niveles diferentes que definen dos dimensiones de la vida moral, por un lado, la privada compuesta por los principios de autonomía y beneficencia, y por otra, la pública formado por los de no-maleficencia y justicia, y se establece que en caso de conflicto entre los mismos, los deberes del nivel público tendrán siempre prioridad sobre los del nivel privado. En este caso el embrión se encontraría en situación de indefensión y, por tanto, con necesidad de protección y tutela, resultando que ética y jurídicamente esta protección se articulará siempre en el mejor beneficio para el tutelado. Por tanto, ante sujetos incapaces o indefensos, se debería de priorizar la obligatoriedad de no maleficencia y justicia sobre el de autonomía personal. 
y así se precisa inicialmente que: «cuando el paciente menor de edad no sea capaz intelectual ni emocionalmente de comprender el alcance de la intervención...», de donde se deriva que lo que debería analizarse en primer lugar -y con independencia de la edad del menor- es si se le considera maduro para comprender el alcance y finalidad de la intervención, ya que -literalmente- se manifiesta que «el paciente menor que no sea capaz», por lo que cabe pensar que «contrario sensu» que el paciente menor sí pueda ser capaz de comprender la intervención, sus efectos y consecuencias, y que en estos casos debería ser él en exclusiva quien debería de prestar el consentimiento, sin intervención de terceros, aún cuando éstos fueran sus padres o representantes. Este aspecto a mi modo de entender nos podría generar confusión y no pocos problemas sobre todo en los casos de rechazo a tratamientos médicos que sin duda podrían salvar la vida del menor.

A renglón seguido se indica que si el menor no tiene capacidad «el consentimiento lo dará el representante legal del menor después de haber escuchado su opinión si tiene doce años cumplidos», lo que obliga a oír en todo caso al mayor de 12 años, y continua "cuando se trate de menores no incapaces ni incapacitados, pero emancipados o con dieciséis años cumplidos, no cabe prestar el consentimiento por representación", es decir, se produce una emancipación anticipada del menor para aspectos sanitarios, pero a renglón seguido se recorta indicando que "sin embargo, en caso de actuación de grave riesgo, según el criterio del facultativo, los padres serán informados y su opinión será tenida en cuenta», en estos últimos casos se nos plantea el problema de quién debe consentir en los supuestos de disensión entre los padres y el hijo, y por último el art. 9.4 de la misma excluye del ámbito de actuación de los menores, aún cuando tengan más de 16 años, algunos supuestos como los ensayos clínicos o la reproducción asistida. Estimo que la redacción de la Ley podría y debía de haber sido más clarificadora.

La literalidad de la Ley no nos ofrece una respuesta clara, y considero que no aborda de forma directa, posiblemente porque no estuviera en la mente del legislador, los problemas que se pueden generar respecto del rechazo de tratamientos médicos que con una alta probabilidad salvarían la vida de un menor o de un incapaz, piénsese en el supuesto que luego abordaremos en el que el menor rechace el tratamiento y sus padres ratifiquen la referida negativa. Por ello considero necesario analizar la casuística y problemas que se pueden plantear con el menor testigo de Jehová.

Es lo cierto, que en estos casos y, sobre todo cuando está en peligro la vida del paciente menor, los facultativos tienden a exigir el 
consentimiento de los padres bien utilizando la representación por ser el paciente menor de 16 años, o bajo la consideración de concurrencia de situación de "grave riesgo» para el supuesto de que el menor tenga más de 16 años (lo que la ley considera un menor maduro) o un emancipado, la intervención de los padres nos puede conducir a diversos supuestos que vamos a analizar:

\section{VI.1. Paciente menor de 16 años y negativa de los padres a la transfusión de sangre en situación de gravedad}

En estos casos, por tratarse de un menor de 16 años, la Ley 41/2002 nos reconduce al consentimiento por representación, y los padres o tutores pudieran manifestar, por entender que es lo mejor para sus hijos o pupilos, su negativa a la aplicación del tratamiento.

No obstante, toda vez que el art. 9.5 de la Ley 41/2002 dispone que el consentimiento por representación debe prestarse «siempre a favor del paciente y con respeto a su dignidad personal», a mi modo de entender, en base a este precepto, si el facultativo duda de que el consentimiento por representación respete la dignidad del menor debe solicitar el auxilio e intervención de la autoridad judicial.

Lo mismo ocurrirá cuando el menor se manifieste a favor de que se le realice la transfusión y los padres o tutores se nieguen por razones religiosas, en estos casos, además de que el art. 9.5 de la Ley determina para el menor o incapaz que «el paciente participará en la medida de lo posible en la toma de decisiones a lo largo del proceso sanitario", el hecho de que los padres se nieguen a que se le aplique un tratamiento que el menor admite, constituye una prueba más de que el consentimiento por representación no se está llevando «en interés del paciente» con respeto a "su dignidad personal», sobre todo si se ve comprometido su derecho a la vida o a su integridad.

En cuanto al problema relativo sobre qué resulta más digno para el menor, el respetar su derecho a la vida o, por el contrario, su derecho a la libertad ideológica y religiosa, habría que aplicar, en mi modesta opinión, por tratarse de un menor de edad, el criterio del principio de proporcionalidad a favor del derecho a la vida en cuanto que es sustrato material para el ejercicio de los demás derechos, partiendo de la base de que se trata de una decisión de consecuencias irreversibles, no susceptible de modificación tras una posterior evolución o maduración de la personalidad del menor, y procurar que el menor alcance la mayoría de edad, para que con plena capacidad 
sobre sus creencias y convicciones, una vez alcanzada, decida lo que corresponda ${ }^{41}$. Por ello, puede afirmarse la existencia de un deber de los padres de asegurar las condiciones para que el menor pueda alcanzar la mayoría de edad, y que sea el hijo quien pueda en un futuro adoptar sus propias decisiones y asumir sus consecuencias en plena capacidad ${ }^{42}$.

$\mathrm{Y}$ es que la vida de un sujeto menor no puede quedar condicionada a las creencias religiosas de terceros, aún cuando esos terceros sean sus padres o tutores, operando el límite establecido en el art. 3.1 de la L.O. 7/1980 de Libertad Religiosa que reconoce como tal el respeto a los derechos fundamentales de los demás, en este casos de sus hijos o pupilos.

\section{VI.2. Pacientes menores de edad, pero mayores de 16 años, que aceptan el tratamiento y sus padres o tutores lo rechazan}

En estos casos, como he adelantado, los padres serán oídos y su opinión tenida en cuenta por tratarse de una situación de "grave riesgo", pero, entiendo que, quien sigue consintiendo es el menor maduro (la ley indica que en estos casos «no cabrá la representación»), y por lo tanto habría que atender a su manifestación.Sería de aplicación aquí lo ya señalado en el punto anterior, relativo a que los padres o tutores no pueden condicionar la vida de sus hijos o pupilos

${ }^{41}$ Véase FERREIRO GALGUERA, en "Libertad de conciencia contra legem...», pág. 154 ss., donde indica que para evitar el conflicto entre los padres y los hijos menores se articula un procedimiento que es el siguiente para estos casos: «el Estado, representado en el Poder Judicial, se subroga momentáneamente en el papel de garante, $\mathrm{y}$, en ejercicio de la patria potestad que asume interinamente, otorgaría a los facultativos la autorización pertinente para realizar la necesaria transfusión. De esta forma, se respetaría al menos el contenido esencial de la libertad religiosa de los padres que no se verían impelidos a actuar en contra de sus creencias. Los padres actuarían conforme a derecho siempre que declarada su oposición por motivos religiosos, acataran la decisión del Juez que ordena la transfusión. Esto es, si acatan la decisión del Estado de subrogarse momentáneamente en su papel de guardador para proteger en última instancia el derecho prevalente».

${ }^{42}$ En la página web de página de Anestiosología Mexicana en Internet el artículo sin firmar titulado «Testigos de Jehová y Hemotransfusión», http://www.anestesia. com.mx/art-17.html (entrada revisada el 25/11/2011), se señala que en el caso de menores y embarazadas en los Estados Unidos muchas cortes abogan a favor de la vida del niño indicando la necesidad de hemotransfundir aunque el padre y /o la madre estén en desacuerdo. Citando una decisión de la Suprema Corte de Justicia en los E.U.N. en 1944: «los padres son libres de ser mártires por decisión propia, pero eso no les permite, en idénticas circunstancias, el volver mártires a sus hijos antes de que éstos hayan alcanzado la edad suficiente para tener criterio amplio y legal para decidir por ellos mismos». 
en base a lo que ellos crean o dejen de creer (art. 3.1 L.O. 7/1980 de Libertad Religiosa), lo que fundamentaría la resolución a favor de la aplicación del tratamiento médico. No obstante, entiendo que en estos casos, para evitar cualquier problema y por razones de seguridad, a efectos prácticos se solicite por el profesional sanitario, autorización judicial al respecto.

\section{VI.3. Pacientes menores con 16 años cumplidos que rechacen el tratamiento, y sus padres o tutores ratifiquen la negativa}

Este es el supuesto que más problemas puede generar si atendemos en exclusiva al tenor literal de la Ley 41/2002, ya que como hemos indicado en estos casos "no cabrá el consentimiento por representación ${ }^{43}$, y por tratarse de situación de "grave riesgo" la Ley determina que los padres "serán informados y su opinión tenida en cuenta». En estos casos si ambos (padres e hijo) rechazan la transfusión, tendríamos a un menor de edad (16 años) que podría fallecer cuando a ciencia cierta, o con una probabilidad muy alta, en algunos casos, una transfusión de sangre le salvaría la vida.

Me pregunto en estos casos ¿no se está anticipando con estos preceptos una emancipación que trasciende del ámbito sanitario, por ejemplo en este caso, sobre cómo pueden condicionar a su propia vida las creencias religiosas?, ¿puede ser maduro para consentir o rechazar tratamientos, y no para determinar una madurez en materia religiosa y sobre los efectos y consecuencias que para el conjunto de su vida plantea la religión que profesa?, ¿podría un médico considerar en este caso que el paciente menor está condicionado en su decisión por los dogmas de una religión y que su decisión podría tener consecuencias irreversibles, y pedir que sea un Juez el que decida?, ¿pretendía el legislador que la redacción dada al art. 9.3 de la ley 41/2002 que un menor de edad con 16 años pudiera consentir exclusivamente sobre la aplicación o no de tratamientos de los que puede depender la vida?, y lo que es más complicado ¿cuál sería la decisión del Juez, y en que se basaría?

${ }^{43}$ ROMEO CASABONA, EMALDI CIRIÓN, ESCAJEDO SAN EPIFANIO, NICOLÁS JIMÉNEZ, ROMEO MALANDA, URRUELA MORA, en La ética y el derecho ante la biomedicina del futuro, Universidad de Deusto, Bilbao, 2006, pág. 65 señalan que «pese a que el ordenamiento jurídico excluye la representación en el ámbito de los derechos personalísimos, ello no hace desaparecer el deber del Estado y de padres o tutores de proteger los intereses de los sujetos menores de edad, de tal forma que deberán emplear los medios que sean necesarios para proteger la salud de los mismos hasta que alcancen la mayoría». 
El problema se podría haber solucionado si se hubiera introducido en la Ley 41/2002 un precepto que estableciera que cuando se trata de aplicar, o de no aplicar, un tratamiento médico a personas menores de edad y, por lo tanto, menores de 18 años, siempre que exista riesgo para su vida o grave afectación a la integridad física o psíquica del menor, se debiera de solicitar previamente autorización judicial, de modo similar a lo que dispone el Código de Familia Catalán ${ }^{44}$ o el art. 25.3 de la Ley extremeña 3/2005 de 8 de julio.

No obstante creo que, entretanto procede para estos casos una aplicación conjunta del Ordenamiento Jurídico, y no sólo aislada de los preceptos de la Ley 41/2002. Así, sin dejar de considerar que la persona con 16 años cumplidos es todavía menor de edad (mayoría de edad que sólo se alcanza a los 18 años), seguirá, en cuanto que es todavía menor de edad, estando sometido a las reglas de la patria potestad, y por lo tanto, a los padres les serían exigibles el cumplimiento de los deberes inherentes a la misma, máxime cuando se trata de una decisión de consecuencias irreversibles.

De esta manera, del art. 39 CE en relación con los arts. 110 y 154 CC imponen el deber de «velar» por los hijos, lo que sin duda incluye el deber de cuidar de su salud, lo que me lleva a la consideración de que, aunque los hijos menores de edad sean maduros, ello no elimina el deber de sus progenitores de procurarles en todo momento la asistencia que estos requieren, lo que necesariamente abarca a los actos de velar por su salud incluso contra su voluntad si es preciso $^{45}$. El deber de los padres de velar por sus hijos no puede desaparecer por la voluntad del menor.

${ }^{44}$ Determina en su art. 255.3. del Código de Familia Catalán que «en el caso en que se pretendan aplicar tratamientos médicos que puedan poner en peligro la vida o integridad física o psíquica de la persona afectada, es de aplicación lo establecido en el artículo 219 para estos tratamientos», y el art. 219.1. determina que «la persona titular de la tutela necesita autorización judicial para: a) Internar a la persona incapacitada en un establecimiento adecuado. b) Aplicar a la persona incapacitada tratamientos médicos que fundamentalmente puedan poner en grave peligro su vida o su integridad física o psíquica. 2. Las medidas indicadas en el apartado 1 pueden ser tomadas sin autorización previa si el hecho de su obtención puede suponer un retraso que implique un grave riesgo para la persona tutelada, para otras personas o para los bienes. En este caso, debe comunicarse al Juzgado que corresponda y al consejo de tutela, si lo hay, la decisión adoptada, en el plazo de veinticuatro horas, como máximo».

${ }^{45}$ Véase el mismo razonamiento en ROMEO CASABONA, EMALDI CIRIÓN, ESCAJEDO SAN EPIFANIO, NICOLÁS JIMÉNEZ, ROMEO MALANDA, URRUELA MORA, en La ética y el derecho ante la..., pág. 65, también se pone como ejemplo el 154 $\mathrm{CC}$ relativo a la patria potestad y a las obligaciones que de ella se derivan, declarando que «el deber genérico de velar por los hijos sujetos a la patria potestad engloba el 
Y para aquellos casos en los que padres incumplan sus obligaciones, entre ellos las de velar por la vida del menor, o no las atiendan de forma correcta, el art. 158.4 CC faculta a la intervención judicial, incluso de oficio, para cualquier «disposiciones que considere oportunas, a fin de apartar al menor de un peligro o de evitarle perjuicio».

Además, la consideración global de nuestro Ordenamiento Jurídico nos pone también de manifiesto que existen suficientes ejemplos en la normativa de que los menores de edad, aunque posean una cierta capacidad de juicio, no llegan a adquirir en ningún caso la misma capacidad de obrar que se predica de las personas mayores de edad ${ }^{46}$.

A lo anterior, podemos añadir además tres razones esenciales:

1. El art. 2.1 de la LO 1/1996 de Protección Jurídica del Menor, establece que: "primará el interés superior de los menores sobre cualquier otro interés legítimo que pudiera concurrir», nos conduce necesariamente a la regla de la proporcionalidad de derechos, y entre la vida del menor y su libertad religiosa o su incolumidad corporal, estimo que, por tratarse de una decisión de consecuencias irreversibles, debe prevalecer el primero de ellos, por lo menos, hasta que éste alcance su mayoría de edad.

La STS 565/2009 de 31 de julio estableció una serie de criterios o procedimientos para determinar e interpretar el concepto «interés del menor», y señaló que se identificaba «en primer lugar con proveer, por el medio más idóneo, a las necesidades básicas o vitales del menor (alojamiento, salud, alimentación...), y a las de tipo espiritual adecuadas a su edad y situación; las afectivas, educacionales, evitación de tensiones emocionales y problemas», y a renglón seguido añade: "se deberá atender a los deseos, sentimientos y opiniones del menor siempre que sean compatibles con lo anterior...». De ello, se puede derivar una interpretación jerarquizada que prescribe la necesidad de atender

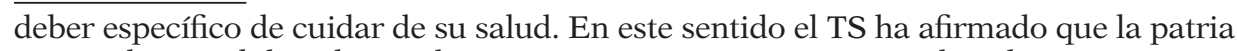
potestad es en el derecho moderno, y concretamente en nuestro derecho positivo, una función al servicio de los hijos, que entraña fundamentalmente deberes a cargo de los padres encaminados a prestarles asistencia de todo orden (STS 24 de abril de 2000)».

${ }^{46}$ Verbigracia: véase la falta de sufragio activo y pasivo (arts. 2 y 6 de la LOREG 5/1985), y en el ámbito civil el art. 323 CC excluye para los menores emancipados determinadas actuaciones (tomar dinero a préstamo, gravar o enajenar bienes inmuebles y establecimientos mercantiles o industriales u objetos de extraordinario valor) sin consentimiento de sus padres o curador. En el ámbito laboral, se impide la contratación de menores de 16 años, y en todo caso el ET prevé que los menores de 18 años no podrán realizar trabajos nocturnos ni los declarados penosos, insalubres, nocivos o peligrosos para la salud, ni realizar horas extraordinarias (véase arts. 6.2 y 6.3 del RD-Legislativo 1/1995, de 24 de marzo, por el que se aprueba el Estatuto de los Trabajadores). 
primariamente a las necesidades básicas, entre las que se encuentra la de garantizar la salud del menor, por encima de otros criterios.

2. En el propio ámbito sanitario, no se puede desconocer que el art. 9.3 de la Ley 41/2002 después de reconocer la capacidad de los menores maduros, a renglón seguido la limita para los casos de "grave riesgo», e incluso el art. $\mathbf{9 . 4}$ recogen unas excepciones a la regla general del consentimiento del menor, indicando que sólo el mayor de edad puede consentir sobre la realización de ensayos clínicos, reproducción asistida, o incluso en otras normativas (se prohíbe la esterilización, o el trasplante de órganos o la cirugía transexual de menores (art. $156 \mathbf{C P}$ ), la donación de órganos (art. 155 CP), y el art. 7 del RD 1301/2006 de 10 de noviembre prohíbe también la extracción de células y tejidos de menores, salvo supuestos muy excepcionales. Todos estos preceptos concluyen que el menor no sea el protagonista exclusivo de la decisión cuando se trate de supuestos en los que se ponga seriamente en peligro su salud o su vida, como ocurre en los supuestos de rechazo a un tratamiento médico en circunstancias de gravedad ${ }^{47}$.

3. Y en tercer lugar se añade: «muy significativo de lo anterior es el hecho de que el legislador ha vetado a los menores de edad la posibilidad de emitir instrucciones previas o voluntades anticipadas» (art. 11 Ley 41/2002), teniendo en cuenta que la voluntad comúnmente más vinculada a esta figura será la de rechazar un tratamiento vital $^{48}$.

${ }^{47}$ Véase MARCOS DEL CANO, A.M., y DÍEZ RODRÍGUEZ, J.R., «Bioethics and health law: the living will. Proposal to create a living will record», en in Europe.25th IVR World Congress: Law, Science and Technology, pp. 1-4. (Alemania): 2012.ISBN urn:nbn:de:hebis:30:

${ }^{48}$ El Art. 11.1 de la Ley 41/2002 que señala: «Por el documento de instrucciones previas, una persona mayor de edad, capaz y libre, manifiesta anticipadamente su voluntad, con objeto de que ésta se cumpla en el momento en que llegue a situaciones en cuyas circunstancias no sea capaz de expresarlos personalmente, sobre los cuidados y el tratamiento de su salud o, una vez llegado el fallecimiento, sobre el destino de su cuerpo o de los órganos del mismo. El otorgante del documento puede designar, además, un representante para que, llegado el caso, sirva como interlocutor suyo con el médico o el equipo sanitario para procurar el cumplimiento de las instrucciones previas.»Alguna normativa autonómica permite a los menores emancipados otorgar instrucciones previas Véase el art. 4 de la Ley 5/2003, de 9 de octubre de Andalucía, el art. 1 del Decreto valenciano 168/2004 de 10 de septiembre, también permite a los menores no emancipados otorgar instrucciones previas (art. 1), lo mismo en el art. 17 de la Ley 1/2003 de la Comunidad Valenciana, art. 54 de la Ley Foral Navarra 17/2010, de 8 de noviembre. Respecto de la contradicción entre la normativa básica estatal de la Ley 41/2002 y las discrepancias de las leyes autonómicas, y su posible inconstitucionalidad véase ROMEO CASABONA, EMALDI CIRIÓN, ESCAJEDO SAN EPIFANIO, NICOLÁS JIMÉNEZ, ROMEO MALANDA, URRUELA MORA, en La ética y el derecho ante la..., pág. 101 ss, y también GONZALEZ SALINAS P., en «El 
Y es que el art. 9.3 c) de la Ley 41/2002, que presume la capacidad y madurez del menor con 16 años cumplidos, no puede presentarse como una regulación autónoma, dictada al margen del conjunto del Ordenamiento Jurídico y de la capacidad que al menor se le reconoce en el mismo, ni puede ignorar el conjunto de obligaciones que se imponen a los representantes legales y al Estado en materia de guarda y protección de los mismos, ni estas funciones desaparecen porque así lo desee el menor de edad, ni los padres o tutores ${ }^{49}$.

Este parece haber sido también el criterio mantenido por los tribunales norteamericanos, si bien justificando sus resoluciones en el criterio de la presencia de un «interés predominante del Estado» materializado en el deber de proteger a personas especialmente vulnerables como los menores e incapaces ${ }^{50}$.

Por todo lo que acabo de exponer, considero que la libertad de conciencia y de religión no se garantiza de forma absoluta e incon-

alcance del carácter básico de la Ley Reguladora de la Autonomía del Paciente y su influencia en las Leyes Autonómicas sobre la misma materia». en GONZÁLEZ SALINAS, P. y LIZARRAGA BONELLI, E. (Coord.), en Autonomía del paciente, información e historia clínica, págs. 15 ss.

49 Véase ROMEO CASABONA, EMALDI CIRIÓN, ESCAJEDO SAN EPIFANIO, NICOLÁS JIMÉNEZ, ROMEO MALANDA, URRUELA MORA, en La ética y el derecho ante la..., pág.70, señalan que: «si nos encontramos ante un menor inmaduro, ante la negativa de los padres o de los representantes legales a que se realice la transfusión, el médico podrá, o bien practicarla si existe un grave peligro para la vida del menor, o bien, acudir al Juez para que este lo autorice si tal urgencia no existe». Y más adelante «a esta misma conclusión debemos llegar si el menor reúne las condiciones de madurez suficientes (incluso si se trata de un menor mayor de 16 años o de un menor emancipado), pues la libertad de autodisposición sobre el propio cuerpo y la libertad religiosa deben ceder a favor de la protección a su vida, al menos hasta que se llegue la mayoría de edad».

${ }^{50}$ FERREIRO GALGUERA, J., en «Libertad de conciencia contra legem...»:, pág. 144 ss narra el caso Matter of Melideo (1976) en la que el Sr. Melideo, testigo de Jehová, como consecuencia de una operación sufrió una fuerte hemorragia, y rechazó la transfusión. La Corte Suprema de Nueva York concluyó que no se le podía obligar judicialmente a un adulto que rechaza la transfusión, salvo cuando existiera un interés predominante del Estado (compelling state interest) que lo justifique. Eran intereses predominantes del Estado: 1. la protección de los supuestos de incapacidad el paciente para asumir una decisión sobre su vida, en cuyo caso sería el Estado el que sumía su decisión. Si bien algunas sentencias revindicaban la doctrina del subtituted judgement, por la cual, obliga a tener en cuenta cual hubiera sido las preferencias del paciente si hubiera podido decidir por sí mismo. Esta doctrina se aplicó en el caso In re Boy en la que se decidió no administrar tranquilizantes a una anciana esquizofrénica miembro de la Christian Science. 2. Interés de menores y nasciturus, que comprendía incluso los supuestos en los que el paciente que se negara tuviera a su cargo hijos menores o incapaces. 3. La salud pública (...). Ya en 1934 el Tribunal Supremo afirmó que el derecho de practicar una religión no incluía el derecho a exponer a la comunidad o las propios hijos a enfermedad infecciosa (Prince vs Massachussets). 
dicionada ${ }^{51} \mathrm{y}$, en caso de conflicto o colisión, pueden estar limitadas por otros derechos constitucionalmente protegidos, especialmente

${ }^{51}$ En cuanto a estos límites a la libertad religiosa y los menores resulta paradigmático el pronunciamiento contenido en la STC 141/2000, de 29 de mayo que trae causa en un supuesto de separación matrimonial en el que la mujer alegaba y pedía la limitación y restricción del régimen de visitas de su ex-marido en relación con los dos hijos habidos en el matrimonio -ambos menores de edad (de cinco y doce años)-, como consecuencia de su pertenencia al denominado Movimiento Gnóstico Cristiano Universal de España y por el proselitismo que de su ideario hacía tanto para con su esposa como para con sus hijos. El Juzgado de Instancia además de acordar la extinción del matrimonio determinó atribuir su guarda y custodia a la esposa, compartiendo ambos progenitores la patria potestad, y estableciendo como régimen de visitas a favor del padre los fines de semana alternos desde las veinte horas del viernes hasta las veinte horas del domingo, la mitad de las vacaciones de Navidad, Semana Santa, Fallas y de verano, añadiendo, con prohibición expresa al padre de hacer partícipe a sus hijos de sus creencias religiosas así como la asistencia de los menores a cualquier tipo de acto que tenga relación con aquéllas. La mujer apeló, y la Audiencia Provincial de Valencia, estimando parcialmente el recurso de apelación, acordó respecto del régimen de visitas su limitación a fines de semana alternos desde las diez horas hasta las veinte horas, sábados y domingos, sin pernoctar en domicilio del apelado, suprimiendo todos los períodos vacacionales, confirmando la sentencia de instancia en el resto de sus pronunciamientos, con la finalidad de "preservar el interés de los menores», y fundó su resolución principalmente en el informe psicosocial que constaba en las actuaciones, de cuyas conclusiones se subrayó la circunstancia de que el citado movimiento podía ser una secta destructiva, aconsejando la adopción de medidas que impidiesen al padre hacer partícipe a sus hijos de las creencias profesadas por él como miembro de aquella, habida cuenta de la corta edad de los menores (doce y cuatro años) y su vulnerabilidad. Esta sentencia no obstante hace unas consideraciones esenciales respecto de la dimensión externa e interna de las manifestaciones religiosas, la incidencia sobre el sujeto propio o sobre terceros, y sobre todo habla del límite a la libertad religiosa marcado por el respeto a los derechos humanos y otros bienes jurídicos protegidos constitucionalmente. Se determinó en la misma que si bien la libertad de creencias, sea cual sea su naturaleza, religiosa o secular, representa el reconocimiento de un ámbito de actuación constitucionalmente inmune a la coacción estatal garantizado por el art. 16 C.E., sin más limitación, en sus manifestaciones, que las necesarias para el mantenimiento del orden público protegido por la ley, y que por lo tanto se ampara, pues, un «agere licere» consistente en profesar las creencias que se desee y conducirse de acuerdo con ellas, así como mantenerlas frente a terceros y poder hacer proselitismo de las mismas.

Véase ROMEO CASABONA, EMALDI CIRIÓN, ESCAJEDO SAN EPIFANIO, NICOLÁS JIMÉNEZ, ROMEO MALANDA, URRUELA MORA, en La ética y el derecho ante la..., pág. 69 , indica que «así pues, en las condiciones actuales el interés superior del menor, entre otros, ha de ser el de preservar su vida para que pueda ejercer con plenitud todos los demás derechos cuando alcance la mayoría de edad. De esta forma el reconocimiento excepcional de la capacidad del menor respecto de determinados actos jurídicos no es suficiente para reconocer la eficacia jurídica de un acto como el ahora contemplado (la negativa al tratamiento) que por afectar en sentido negativo a la salud o a la vida, tiene como notas esenciales la de ser definitivo y en consecuencia irreparable. 
cuando los que resultan afectados son los derechos de otras personas $\mathrm{y}$, sobre todo, si son menores de edad ${ }^{52}$.

En este sentido no puedo más que lamentar, una vez más, como ha realizado ya diversa doctrina, lo desacertado, desde mi punto de vista, de la Sentencia del Pleno del Tribunal Constitucional 154/2002, de 18 de julio, que aunque entiendo las razones de política criminal que pudieron conducir a su pronunciamiento, creo que es constituye un mal precedente ${ }^{53}$.

${ }^{52}$ Tampoco entiendo que este parecer se pueda ver alterado como consecuencia de una hipotética invocación por los seguidores de los testigos de Jehová de otro derecho fundamental- de su derecho a no ser discriminado por razón de credo o religión (art. 14 CE)-, ya que estimo que las diferentes creencias no pueden sustentar diferencias de trato jurídico, como señala numerosa jurisprudencia, la religión "posee una distinta intensidad según se proyecte sobre la propia conducta y la disposición que sobre la misma haga cada cual, o bien lo haga sobre la repercusión que esa conducta conforme con las propias creencias tenga en terceros, sean estos el propio Estado o los particulares».

${ }^{53} \mathrm{El}$ presupuesto fáctico de este pronunciamiento trae su causa de las lesiones sufridas a consecuencia de la caída de una bicicleta de un menor de trece años que fue ingresado en un hospital de Lérida. Los médicos consideraron necesario para salvaguardar su vida proceder de inmediato a una transfusión de sangre. Los padres -testigos de Jehová- se opusieron por motivos religiosos-, a pesar de haber sido informados del riesgo que corría su hijo y de que no había otros tratamientos alternativos. Prescindiendo de la voluntad de los padres de trasladar a su hijo a otro centro hospitalario, se solicitó del Juzgado de Guardia autorización para la práctica de la transfusión, que fue concedida. No obstante, la transfusión no se realizó, habida cuenta de que el menor la rechazó «con auténtico terror». Los padres acataron la autorización judicial, pero se negaron a colaborar con el personal sanitario del centro para convencer a su hijo sobre la procedencia de la transfusión. La misma situación se reprodujo en días sucesivos en otros dos centros hospitalarios. Finalmente, al quinto día, los padres trasladaron al menor a su domicilio (provincia de Huesca), donde, a petición del Ayuntamiento, el Juzgado de Instrucción autorizó la entrada en el domicilio con el fin de asistencia médica en los términos que estimaran pertinentes el facultativo y el médico forense, incluida una transfusión. Trasladado su hijo a un centro hospitalario se realizó la transfusión de sangre, que resultó tardía. El menor falleció al día siguiente. Resulta probado que, de haberse realizado a tiempo la transfusión, el menor habría sobrevivido con una muy alta probabilidad. Mientras que la Audiencia Provincial de Huesca consideró que los hechos relatados no constituían delito alguno, la Sala 2. ${ }^{a}$ del Tribunal Supremo condenó a los progenitores del menor «como autores responsables de un delito de homicidio, con la concurrencia, con el carácter de muy cualificada, de la atenuante de obcecación o estado pasional, a la pena de dos años y seis meses de prisión». La STS entendió que los padres no habían ejercido las funciones y cumplido los deberes propios de la patria potestad al no autorizar la transfusión de sangre, no evitando -como les era exigible- el resultado de muerte, que, de haber prestado su consentimiento, no se habría producido. Partiendo de esta premisa de que los padres tenían el deber de hacer todo lo que fuere preciso para salvar la salud y la vida de su hijo, resulta que aquéllos incurrieron en dolo eventual. Por el contrario, el Tribunal Constitucional anula la sentencia anterior y considera que el ejercicio del derecho a la libertad religiosa y del derecho a la integridad física por parte del menor, al negarse a recibir una transfusión de sangre, no vinculaba a los padres. 
Y en concreto respecto de la controversia que se plantean en la referida Sentencia sobre si existía o no posición de garante de los padres ${ }^{54}$, el TC -en discrepancia con el TS- indicó que estos deberes quedaron debidamente cumplimentados desde el momento en que los progenitores acataron las decisiones judiciales y habida cuenta que procuraron en todo momento proporcionar cuidados médicos a su hijo ${ }^{55}$, y que esos deberes no les obligaban a autorizar la transfusión $\mathrm{y}$, mucho menos, a tratar de convencer a su hijo para que éste la consintiera, ya que semejante exigencia era contraria a la voluntad del menor ${ }^{56}$, a las convicciones religiosas de los propios padres

${ }^{54}$ Véase también ROMEO CASABONA, C.M., en "¿Límites de la posición de garante de los padres respecto al hijo menor? (La negativa de los padres, por motivos religiosos, a una transfusión de sangre vital para el hijo menor)», Revista de Derecho Penal y Criminología, n. ${ }^{\circ 2}$, 1998, pág. 334, indica que «la intervención del Juez, autorizando la transfusión para el caso de que fuera imprescindible, no elimina, en este caso, la posición de garante de los padres».Y véase también ROMEO CASABONA, EMALDI CIRIÓN, ESCAJEDO SAN EPIFANIO, NICOLÁS JIMÉNEZ, ROMEO MALANDA, URRUELA MORA, en La ética y el derecho ante la... pág.72,véase también la nota al pie n. ${ }^{\circ} 102$ en la misma página, donde se indica que la posición de garante exige una «actuación positiva encaminada a tal fin (que no puede quedarse única y exclusivamente en acudir a un centro hospitalario si luego se ponen objeciones al tratamiento ofertado), y completa en la nota al pie que «Cuestión distinta es que estando los padres de acuerdo con el tratamiento y aceptando la transfusión de sangre, el hijo se oponga a ello. La responsabilidad sobre los efectos perjudiciales para la salud de aquel caerán en su caso sobre los médicos que traten el menor si no hacen todo lo posible para salvarle la vida. Los padres poco más pueden hacer en dicha situación. Sin embargo, en este caso los padres no sólo no asumen el tratamiento ofrecido, sino que al mostrase en desacuerdo con el mismo (aunque no se opusieran a este) se llevan al hijo del hospital en dos casos. Este hecho refuerza la existencia de una posición de garante de los padres, que debieron decidir en distintos momentos y lugares sobre la transfusión».

${ }^{55} \mathrm{Al}$ contrario que la posición anterior FERREIRO GALGUERA, en «Libertad de conciencia contra legem...», pág. 157, después de preguntarse si los padres han de tratar de convencer a su hijo para que se realizara la transfusión hasta el punto de intentar convencer a su hijo para que actúe en contra de las creencias que le habían transmitido a lo largo de la vida, se muestra en apoyo de la doctrina del TC, manifestando que «ese sacrificio no es admisible porque implica una vulneración del contenido esencial de la libertad religiosa. Obligar a una persona a actuar en contra de sus convicciones contradice en su propio núcleo el derecho a la libertad religiosa: Además supone trasladar a los padres la adopción de una decisión desechada por los médicos, e incluso por la autoridad judicial-, una vez conocida la reacción del menor».

${ }^{56}$ FERREIRO GALGUERA, en «Libertad de conciencia contra legem...», pag.157 señala que: «tan sólo la asunción por parte de los padres de la decisión del Estado de subrogarse momentánea y puntualmente en la titularidad de la patria potestad sobre su hijo y de las consecuencias que ello conlleve. Al acatar la autorización del Juez que ordenaba la y transfusión (decisión dirigida a la salvaguarda de la vida del menor), los padres actuaban conforme a derecho». En el mismo sentido, véase MARÍN GÁMEZ, J.A., en «La negativa de los representantes del menor o incapaz a practicar transfusiones de sangre. Una perspectiva jurisprudencial», en, GALLADO 
y a las enseñanzas que habían ido transmitiendo a aquél a lo largo de su vida ${ }^{57}$.

Desde mi punto de vista, y tratándose de un menor de edad (de 13 años) los padres sí tienen una posición de garantes ${ }^{58}$, y además no dejaron de estar en ningún momento en el lugar de los hechos, adquiriendo un evidente protagonismo en la decisión de los diversos traslados a casa ${ }^{59}$, y de casa a los diversos hospitales, incrementando el peligro existente más allá de los límites en que podía permanecer tolerado o controlado, sobre todo, una vez que peligra la vida del sujeto ${ }^{60}$.

CASTILLO, M.J. (direct.), y CRUZ BLANCA M.J. (coord.), en La responsabilidad jurídico-sanitaria, La Ley, Madrid, 2011, pág. 564.

${ }^{57}$ Comparar con el criterio contrario que se adoptó en la STS de 15 de abril de 1997, en la que se castiga como coautora de un delito de lesiones a la madre que no hizo nada por impedir las repetidas agresiones cometidas por su marido contra la hija común, con resultado final de lesiones, ni actuó para salvarla una vez se encontraba herida para evitar que fuera descubierta la agresión. En tal caso, aun existiendo posición de garante, no puede hablarse de equivalencia con la causación del resultado, puesto que, al no haber colaborado en la agresión, con su omisión no provocó el peligro para el bien jurídico ni lo incrementó, limitándose a dejar que los hechos transcurrieran por sí mismos, por lo que la responsabilidad penal de la madre se agotaría en un delito de omisión pura (art. $195 \mathrm{CP}$ ).

${ }^{58}$ Véase GIMBERNAT ORDEIG, E., en "Causalidad, omisión e imprudencia,» Anuario de Derecho Penal y Ciencias Penales, 1994-III, pág. 59. Siguiendo la opinión del autor, no basta con la comprobación de la existencia de deberes legales de garante en el ámbito de las relaciones familiares para la tipicidad de la comisión por omisión (lo cual lleva a consecuencias particularmente restrictivas de su admisión entre cónyuges). Sin embargo, respecto a víctimas menores de edad, sí se dan las condiciones para afirmar la equivalencia, pues son un foco de peligro que tiene que ser contrarrestado con medidas de protección encomendadas a las personas más cercanas. TAMARIT SUMALLA, en «Responsabilidad penal de terceros ante la negativa a la transfusión de sangre de testigo de Jehová menor de edad con resultado de muerte, pág. 4, aprecia para estos casos «una disminución de la culpabilidad, en concreto de la exigibilidad de la conducta adecuada», pero considera sancionable el hecho.

${ }_{59}$ Por el contrario, ROMEO CASABONA C.M., en "¿Límites de la posición de garante de los padres respecto al hijo ......», pág 340, señala que el tema hay que analizarlo desde el punto de vista de la culpabilidad y valorar si esta puede quedar excluida por aplicación del principio de no exigibilidad de obediencia al derecho, indicando que: «no es exigible tal obediencia, puesto que aún manteniendo la posición de garante y existiendo la obligación de persuadir a su hijo, no se les puede exigir, sin embargo, que vaya más allá de la autorización que debían haber otorgado inicialmente incluso en contra de sus propias convicciones religiosas. La no obstrucción de la decisión judicial, la no intromisión de las actuaciones médicas y la petición no ya de infringir su credo, sino de ir más allá, de hacer renegar de algún modo a su propio hijo de la religión en la que le habían educado, abundan en la no exigibilidad de obediencia al derecho, al producirse un nuevo y más profundo enfrentamiento en sus creencias más firmes y legítimas. Se trata, pues, de un supuesto de inexigibilidad».

${ }^{60}$ Sin embargo, entre pronunciamientos del TC, en relación al derecho del menor a la libertad religiosa, considero más adecuado el de la Sentencia del Tribunal Constitucional de 29 de mayo de 2000 , que precisa que, aunque no puede atribuir- 
Como indica Espinosa Labella, justificar conductas como las que analizamos, que pongan en riesgo la vida de un menor por sus creencias religiosas, es iniciar un camino peligroso que nos puede conducir a verdaderas atrocidades, como lesionar gravemente a otras personas, atentar sobre su integridad moral o incluso sobre su vida. De todos es conocido el escaso valor que se otorga a la vida por ciertas sectas religiosas, cuando no por algunos defensores de ciertas corrientes fundamentalistas dentro de alguna religión. Quienes tienen la custodia o guarda de menores de edad puede incurrir, cuando menos, en el ámbito de la comisión por omisión o en la imprudencia, si no son capaces de controlar el riesgo que generan con su conducta omisiva ${ }^{61}$.

No me parece acertado entender que la libertad religiosa permita a los titulares de la patria potestad liberarse de sus deberes, en los términos que acepta el Tribunal Constitucional en la STC 154/2002, incluso cuando las creencias de aquellos sean compartidas por su hijo menor de edad, aunque sean expresa, indudable e incluso intensamente asumidas por este.

\section{PACIENTES INCAPACES, SEAN O NO MENORES DE EDAD}

La solución para estos casos debe de ser la misma que la establecida en el apartado anterior para los menores de 16 años, la actuación por medio de representante y el límite del art. 3.1 de la L.O. 7/1980 de Libertad Religiosa, con la única particularidad que dispone la Ley 41/2002, según redacción dada por la Ley

se a los padres la decisión sobre estas cuestiones religiosas, sin embargo, no puede tampoco abandonarse al menor en su autonomía, por existir diferentes épocas de madurez y de capacidad otorgada por la ley. Además «sobre los poderes públicos, y muy en especial sobre los órganos judiciales, pesa el deber de velar por que el ejercicio de esas potestades por sus padres o tutores, o por quienes tengan atribuida su protección y defensa, se haga en interés del menor, y no al servicio de otros intereses, que por muy lícitos y respetables que puedan ser, deben postergarse ante el «superior» del niño». Como señalan entre otras las SSTC 215/1994, de 14 de julio [RTC 1994, 215] 260/1994, de 3 de octubre [RTC 1994, 260],60/1995, de 17 de marzo [RTC 1995, 60] 134/1999, de 15 de julio [RTC 1999, 134] ,STEDH Caso Hoffmann vs Austria de 23 de junio de 1993 [TEDH 1994, 35] )». Y así, si bien podemos afirmar la independencia del menor a profesar una religión distinta de las de los padres, con los consiguientes efectos en algunos campos del derecho como el civil, o en materia por ejemplo de enseñanza, otra cosa totalmente distinta, es que con base en tal derecho se pretenda fundar un derecho a la disponibilidad de la vida por parte del menor.

${ }^{61}$ Véase ESPINOSA LABELLA, M., en «Comisión por omisión e imprudencia en e imprudencia en la doctrina y la jurisprudencia», en www. westlaw.es, ref. BIB $2009 / 453$. 
26/2001 de 1 de agosto, que deberá asegurarse de que «el paciente participará en la medida de lo posible en la toma de decisiones a lo largo del proceso sanitario. Si el paciente es una persona con discapacidad, se le ofrecerán las medidas de apoyo pertinentes, incluida la información en formatos adecuados, siguiendo las reglas marcadas por el principio del diseño para todos de manera que resulten accesibles y comprensibles a las personas con discapacidad, para favorecer que pueda prestar por sí su consentimiento».

\section{LA CIRCULAR DE LA FISCALÍA GENERAL DEL ESTADO 1/2012}

La Circular de la Fiscalía General del Estado 1/2012 sobre el tratamiento sustantivo y procesal de los conflictos ante transfusiones de sangre y otras intervenciones médicas sobre menores de edad en caso de riesgo grave viene a clarificar la situación de cómo va actuar la Fiscalía en estos casos, y partiendo del argumento de que el menor con 16 años cumplidos sigue siendo menor y que como tal no podría considerarse a todos los efectos como un mayor de edad, nos conducía necesariamente a extraer del conjunto del Ordenamiento Jurídico, y no sólo de la Ley 41/2002, las facultades que determinan su ámbito de actuación ${ }^{62}$.

En cuanto al sustento de la actuación e intervención del Fiscal en estos casos, parte de que en unos casos existe normativa autonómica en la que se declara prevalente el interés del menor, tal y como ocurre con el art. 11.1 d) de la Ley 6/1995, de 28 de marzo, de Garantías de los Derechos de la Infancia y la Adolescencia de la Comunidad de Madrid donde expresamente se indica que «en todo caso, primará el derecho a la vida del menor», el art. 32 de la Ley 12/2001, de 2 de julio, de Infancia y Adolescencia en Aragón que manifiesta: «en todo caso primará el derecho a la vida del menor $y$, en caso de negativa de las personas antes mencionadas a que se realicen las pruebas o tratamiento, deberá resolver la autoridad judicial de acuerdo con las circunstancias», el art. 10 de la Ley 1/1998, de 20 de abril, de Andalucía que expresa que: "para la realización de cualquier intervención que suponga un riesgo para la vida del niño,

${ }^{62}$ Llega incluso a afirmar la referida Circular en uno de sus párrafos que: «puesto que los menores de edad están en proceso de formación y hasta los 18 años no alcanzan la plena capacidad, se encuentran teóricamente bajo la protección del Estado, por lo que no puede darse relevancia a decisiones propias o de sus representantes legales cuyos resultados sea la muerte u otros de carácter gravemente dañino e irreversible para la salud del menor interesado. Sólo así pueden preservarse las condiciones del futuro ejercicio de la plena autonomía del sujeto». 
se recabará el previo consentimiento de los padres o tutores en los términos establecidos en la legislación vigente. En el caso de negativa de los padres o tutores, primará, el interés del niño»., o - aunque no lo cita expresamente- el art. 255.3 y 219 del Código de Familia Catalán que exige autorización judicial para aplicar o rechazar tratamientos que pongan en grave peligro la vida, o la normativa extremeña sobre información y asistencia sanitaria ${ }^{63}$.

Otras Comunidades Autónomas configuran este instrumento de intervención de la Fiscalía forma más directa y relacionado con la obligación de denunciar, como ocurre con el art. 20 de la Ley 14/2002 de 25 de julio, de Promoción, Atención y Protección a la Infancia en Castilla y León.

En otros casos, el desarrollo autonómico de la Ley estatal 41/2002 de autonomía del paciente, remiten expresamente "a la autoridad competente en virtud de lo dispuesto por la legislación civil» para los casos en los que la decisión del representante sea contraria a los intereses del menor, tal y como ocurre con el art. 6.1d) la Ley 3/2001, de 28 de mayo, de Galicia, o el art. 9.3 de la Ley 1/2003, de 28 de enero, de Valencia, o el 51.3 de la Ley Foral de Navarra 17/2010, de 8 de noviembre.

Toda esta normativa constituye elemento esencial para recabar la intervención en estos casos de la Fiscalía, pero se señala que sin duda lo que constituye el elemento esencial es la previsión del art. $158 \mathrm{CC}$, en el que se dispone que el Juez, de oficio, o a instancia del propio hijo, de cualquier pariente o del Ministerio Fiscal, dictará las disposiciones que estime pertinentes a fin de apartar al menor de un peligro o de evitarle perjuicios.

Por último, termina la referida Circular determinando los trámites procesales que corresponde aplicar en estos supuestos, y los reconduce a los procedimientos de Jurisdicción Voluntaria, regulados en los arts. 1811 y sig. de la LEC de 1881, en base a lo previsto en la Disposición Adicional Primera de la L.O. 1/1996 de 15 de enero de Protección Jurídica del Menor, y se pronuncia a favor de la competencia del Juzgado de Guardia para conocer del asunto, recordando que el procedimiento debería de ser calificado como urgente en su tramitación.

${ }^{63}$ Véase también la normativa Extremeña Ley 3/2005 de 8 de julio, de información y asistencia sanitaria, que indica expresamente en el art. 25.3 que "cuando la decisión del representante legal pueda presumirse contraria a los intereses del menor o incapacitado, deberán ponerse los hechos en conocimiento de la autoridad competente en virtud de lo dispuesto en la legislación civil». 


\section{CONCLUSIONES}

Los testigos de Jehová constituyen un grupo religioso cuyo principal rasgo característico es su interpretación literal de la Biblia, y en base a la misma sus seguidores rechazan las transfusiones de sangre.

Los problemas generados por dicha negativa especialmente en situaciones de gravedad siempre han generado polémicas no siempre fácilmente resolubles, y normalmente han sido los Tribunales los que han aportado la solución jurídica. Nuestra Jurisprudencia ha evolucionado desde una concepción inicial basada en la preeminencia absoluta del derecho a la vida sobre el de la libertad religiosa, hasta una concepción actual más tendente a respetar la voluntad del paciente mayor de edad, libre y capaz.

En todo caso, la consideración que siempre han realizado nuestros Tribunales pasa por enfrentar en estos supuestos el derecho a la vida con el derecho a la libertad religiosa, y ha olvidado, que con independencia de que en dichos pacientes exista de fondo una motivación subjetiva de carácter religioso, también confluye una negativa al tratamiento, y por lo tanto el derecho a su incolumidad corporal (art. $15 \mathrm{CE}$ ). Pasados diez años de la entrada en vigor de la Ley 41/2002 de autonomía del paciente se echa de menos un pronunciamiento en este sentido.

Esta omisión Jurisprudencial, no presupone, a mi modo de entender, que siempre haya que respetar la voluntad del paciente testigo de Jehová, sino que debemos de atender a cada caso en concreto, y a la regla de proporcionalidad de los derechos en liza.

Y así, en los supuestos de pacientes testigos de Jehová mayores de edad y capaces, de conformidad con lo dispuesto en la Ley 41/2002 se debe de respetarse su voluntad, incluso cuando con ello ponga en peligro su vida. El sujeto capaz es libre para elegir y tomar sus decisiones conforme a su proyecto vital. Pero no ocurre lo mismo en los supuestos de la mujer embarazada testigo de Jehová, en cuyo caso operará el límite establecido en el art. 3.1 de la L.O. 7/1980 de Libertad Religiosa, en cuanto no puedan resultar dañados los derechos fundamentales de un tercero (el nasciturus), máxime cuando esta decisión compromete su propia existencia, presupuesto material para el ejercicio de los demás derechos.

En cuanto a los supuestos de testigos de Jehová menores de edad, entiendo que en tanto que es menor- aún cuando se trate de menores mayores de 16 años o menores maduros o emancipados- puede 
afirmarse la existencia de un deber de los padres de asegurar las condiciones para que el menor pueda alcanzar la mayoría de edad, y que sea el hijo quien pueda en un futuro adoptar sus propias decisiones en plena capacidad, ya que se trata de una decisión de consecuencias irreversibles, no susceptible de modificación tras una posterior evolución o maduración de la personalidad del menor.

El sustento de tal actuación se deriva tanto del art. $39 \mathrm{CE}$, como de los art. 110 y $154 \mathrm{CC}$ que imponen el deber de «velar» por los hijos y pupilos, lo que sin duda incluye el deber de cuidar de su salud. Para el supuesto caso de que así no se realice el art. 158.4 CC faculta la intervención judicial a fin de "apartar al menor de un peligro o de evitarle perjuicio». Por otro lado, se aprecia que la capacidad del menor se encuentra limitada, incluso en la Ley 41/2002, para actos de especial trascendencia, por lo que considero que el ámbito de facultades del menor vendrá determinado del conjunto del Ordenamiento Jurídico y del conjunto de la Ley 41/2002, no sólo de la consideración al art. 9.3 de la misma.

En caso de incapaces, la representación debe de realizarse en interés del mismo, lo que supone primar su vida sobre las consideraciones religiosas de sus padres o tutores.

No obstante, a los oportunos efectos de ofrecer una mayor seguridad jurídica, sería conveniente se introdujera en la Ley 41/2002 un precepto que estableciera que cuando se trata de aplicar, o de no aplicar, un tratamiento médico a personas menores de edad siempre que exista riesgo para su vida, o grave afectación a la integridad física o psíquica del menor, se debiera de solicitar previamente autorización judicial, de modo similar a lo que dispone el art. 219.1 y 255.3 del Código de Familia Catalán, o como prevé el art. 25.3 de la Ley extremeña 3/2005 de 8 de julio de información sanitaria y autonomía del paciente.

En este estado de cosas, y antes las dudas interpretativas que planteaba la Ley 41/2002 respecto de los supuestos de negativa a tratamientos médicos en situación de gravedad, y especialmente en el caso de menores la Fiscalía General del Estado ha dictado la Circular 1/2012, para fijar un modo de proceder unívoco en su actuación invocando la aplicación del art. $158 \mathrm{CC}$, y de diversa normativa autonómica en la que se declara prevalente el interés del menor. En cuanto a la tramitación procesal la deriva a los procedimientos de Jurisdicción Voluntaria, y a su conocimiento por el Juzgado de Guardia, recordando que el procedimiento deberá de ser calificado como urgente en su tramitación. 


\section{BIBLIOGRAFÍA}

ARRUEGO RODRÍGUEZ, G.: «El rechazo y la interrupción del tratamiento de soporte vital en el derecho español», en In Dret Revista para el Análisis del Derecho, Barcelona, mayo 2009, en http:// www.indret.com/pdf/620 es.pdf.

BAJO FERNÁNDEZ, M.: «Testigo De Jehová y Transfusión de Sangre», en Http://Www.Eutanasia.Ws/Hemeroteca/Z32.Pdf.

BESIO, M. y BESIO, F.: «Testigos de Jehová y transfusión sanguínea: reflexión desde una ética natural», Revista chilena de obstetricia y ginecología, versión On-line, ISSN 0717-7526, v.71, n.4, Santiago, 2006, en http://www.scielo.cl/scielo.php?pid=S071775262006000400010\&script=sci _arttext

CASAS-MARTÍNEZ, M. L.: «Análisis Bioético del embarazo en Testigos de Jehová y el rechazo transfusional», en http://www.aebioetica.org/archivos/03-BIOETICA-73.pdf.

DÍEZ RODRÍGUEZ, J.R.: en «El derecho del paciente a conocer y a decidir: ¿Quién decide?», en MARCOS DEL CANO, A.M., (coord.), Bioética y derechos humanos, UNED Ciencias Sociales y Jurídicas, Editorial Aranzadi S.A., Cizur Menor (Navarra), 2011. Págs 269 a 318.

DÍEZ RODRÍGUEZ, J.R.: «Instrucciones previas: estudio comparativo de las legislaciones autonómicas y propuestas de mejora», en MARCOS DEL CANO, A.M. (Coord.): Instrucciones previas, voluntades anticipadas, testamento vital: un análisis diez años después (en prensa).

ESPINOSA LABELLA, M.: «Comisión por omisión e imprudencia en la doctrina y la jurisprudencia», en $w w w$. westlaw.es, ref. BIB 2009/453.

FAJARDO, J., IBARRA, S. y PEREZ, C.: «Las Transfusiones Sanguíneas, Testigos de Jehová y Bioética», en el blog Bioética y universo Libre, en http: //bioetica y universolibre.blogspot.com/2009/11/ las-transfusiones-sanguineas testigos.html.

FEINBERG, J.: Harm to Self, Oxford University Press, Oxford, 1986.

FERREIRO GALGUERA, J., en «Libertad de conciencia contra legem: Criterios del Tribunal Constitucional en materia de transfusiones», en Foro Revista de Ciencias Jurídicas y Sociales Nueva Época n. ${ }^{\circ}$ 00/2004, Facultad de Derecho, Universidad Complutense de Madrid, Madrid 2004. Págs. 121 a 159. 
FISCALÍA GENERAL DEL ESTADO CIRCULAR 1/2012.

GARZÓN VALDÉS, E., «¿Es éticamente justificable el paternalismo jurídico?», Doxa, 5, 1988.

GIMBERNAT ORDEIG, E.: "Causalidad, omisión e imprudencia», Anuario de Derecho Penal y Ciencias Penales, t. 47, septiembre-diciembre 1994. Págs 5 a 60.

GOMÉZ SÁNCHEZ, Y.: "La Libertad de Creación y Producción Científica en la Ley de Investigación Biomédica: Objeto, ámbito de aplicación y principios generales de la Ley», en SÁNCHEZ CARO, J y ABELLAN, F. (Coord.) en Investigación Biomédica en España. Aspectos bioéticos, jurídicos y científicos, Editorial Comares, Granada, 2007. Págs 1 a 90.

GONZÁLEZ SALINAS, P.: «El alcance del carácter básico de la Ley Reguladora de la Autonomía del Paciente y su influencia en las Leyes Autonómicas sobre la misma materia» en GONZÁLEZ SALINAS, P y LIZARRAGA BONELLI, E. (Coord.): Autonomía del paciente, información e historia clínica (Estudios sobre la Ley 41/2002 de 14 de noviembre), Thomson Civitas, Cizur Menor (Navarra),2004. Págs 15 a 42.

JUNQUERA DE ESTEFANI, R.: «El paciente y su capacidad de decidir en el ordenamiento español», en JUNQUERA DE ESTEFANI, R. (direct.), Bioética y Bioderecho: Reflexiones Jurídicas ante los retos Bioéticos, Colex, Granada, 2008. Págs. 129 a 154.

LIZARRAGA BONELLI, E.: «La información y la obtención del consentimiento informado en la nueva Ley 41/2002, básica, reguladora de la autonomía del paciente y de derechos y obligaciones en materia de información y documentación clínica», GONZALEZ SALINAS, P. y LIZARRAGA BONELLI, E. (coord.), en Autonomía del paciente, información e historia clínica. (Estudios sobre la Ley 41/2002, de 14 de noviembre), Thomson-Civitas, Madrid, 2004. Págs. 225 a 296.

MARCOS DEL CANO, A. M.: «Los derechos de la mujer y la cultura: ¿un conflicto?», en MARCOS DEL CANO, A,M. (coord.), en Inmigración, multiculturalismo y derechos humanos, Tirant lo Blanch-UNED, Valencia, 2009. Pág. 235 a 256.

MARCOS DEL CANO, A. M.: «La Bioética y el Bioderecho desde los derechos humanos» en MARCOS DEL CANO, A.M., (coord.), Bioética y derechos humanos, UNED Ciencias Sociales y Jurídi- 
El Paciente testigo de Jehová, la negativa al tratamiento...

cas, Editorial Aranzadi S.A., Cizur Menor (Navarra), 2011. Págs. 19 a 45.

MARCOS DEL CANO, A.M., y DÍEZ RODRÍGUEZ, J.R., «Bioethics and health law: the living will. Proposal to create a living will record», en in Europe.25th IVR World Congress: Law, Science and Technology, pp. 1-4.(Alemania): 2012. ISBN urn:nbn:de:hebis:30:

MARÍN GÁMEZ, J.A., en «La negativa de los representantes del menor o incapaz a practicar transfusiones de sangre. Una perspectiva jurisprudencial», en, GALLADO CASTILLO, M.J. (direct.), y CRUZ BLANCA M.J.(coord.), en La responsabilidad jurídicosanitaria, La Ley, Madrid, 2011. Págs. 541 a 579.

MÁRQUEZ, D.: Transfusiones de sangre a testigos de Jehová, en http:// www.extj.org/sangre_temas/sangre_argentina.htm .

MARTÍNEZ MORÁN N.: «La dignidad humana en las investigaciones biomédicas», en MARCOS DEL CANO, A.M. (coord): Bioética, Filosofía y Derecho, Servicios de Publicaciones del Centro de la UNED de Melilla, Aldaba 32, 2004. Págs. 165 a 206.

MEJICA GARCIA, J. M. y DÍEZ RODRÍGUEZ, J. R.: El Estatuto del paciente. A través de la nueva legislación sanitaria estatal, en Thomson-Civitas Monografías, Editorial Aranzadi SA, Cizur Menor (Navarra) 2006.

PARRA LUCÁN, M. A.: La capacidad del paciente para prestar válido consentimiento. El confuso panorama legislativo español en www. westlaw.es, ref. BIB 2003 L28.

PÉREZ MARÍN, M. A.: Inspecciones, registros, e intervenciones corporales. Las pruebas de ADN y otros métodos de investigación en el proceso penal, Tirant lo Blanch monografías 527, Valencia, 2008

PÉREZ TRIVIÑO, J. L.: «Testigos de Jehová: entre la autonomía del paciente y el paternalismo justificado», en InDret Revista para el Análisis del Derecho, en http://www.indret.com/pdf/740_es.pdf.

RETAMALES, A.: Autonomía del paciente: Los testigos de Jehová y la elección de alternativas a la transfusión, en http://www.scielo.cl/ scielo.php?pid=S0717-75262006000400011\&script=sci_arttext.

RODRÍGUEZ MOURULLO, G.: La omisión de socorro en el Código penal, Tecnos, Madrid, 1966.

ROMEO CASABONA, C. M., EMALDI CIRIÓN, A., ESCAJEDO SAN EPIFANIO, L., NICOLÁS JIMÉNEZ, P., ROMEO MALANDA, S. y

(C) UNED. Revista de Derecho UNED, núm. 11, 2012 
URRUELA MORA, A.: La ética y el derecho ante la biomedicina del futuro, Universidad de Deusto, Bilbao, 2006.

ROMEO CASABONA, C. M.: «¿Límites de la posición de garante de los padres respecto al hijo menor?» (La negativa de los padres, por motivos religiosos, a una transfusión de sangre vital para el hijo menor), Revista de Derecho Penal y Criminología, n. ${ }^{\circ}$ 2, 1998.

ROMEO MALANDA, S.: «Un nuevo marco jurídico-sanitario: la Ley 41/2002, de 14 de noviembre, sobre derechos de los pacientes (I y II)», en La Ley, Tomo I, núms. 5.703 y 5.704, de 23 y 24 de enero de 2003. Pags. 1522 a 1539.

SANTAMARÍA, L.: Testigos de Jehová, transfusiones de sangre y mortalidad materna en la página web de la Red iberoamericana de estudios de sectas (RIES)http://infocatolica.com/blog/infories. php/testigos-de-jehova-transfusiones-de-sang

SEOANE, J. A.: «El perímetro de la objeción de conciencia médica» en In Dret Revista para el Análisis del Derecho, Barcelona, Octubre de 2009, y en www.raco.cat/index.php/InDret/articlel viewFile/141382/192893ttp.

TAMARIT SUMILLA, J. M: «Responsabilidad penal de terceros ante la negativa a la transfusión de sangre de testigo de Jehová menor de edad con resultado de muerte», en www.westlaw.es 